US Army Corps

of Engineers ${ }_{\circledast}$

Engineer Research and

Development Center

\title{
Electronic Railroad Inspection Database System for Military Facilities
}

T. Jeremy Beasley, Anthony J. Falls, Chad A. Gartrell,

Lora L. Johnson, Judy Reagan, and Caleb Carter

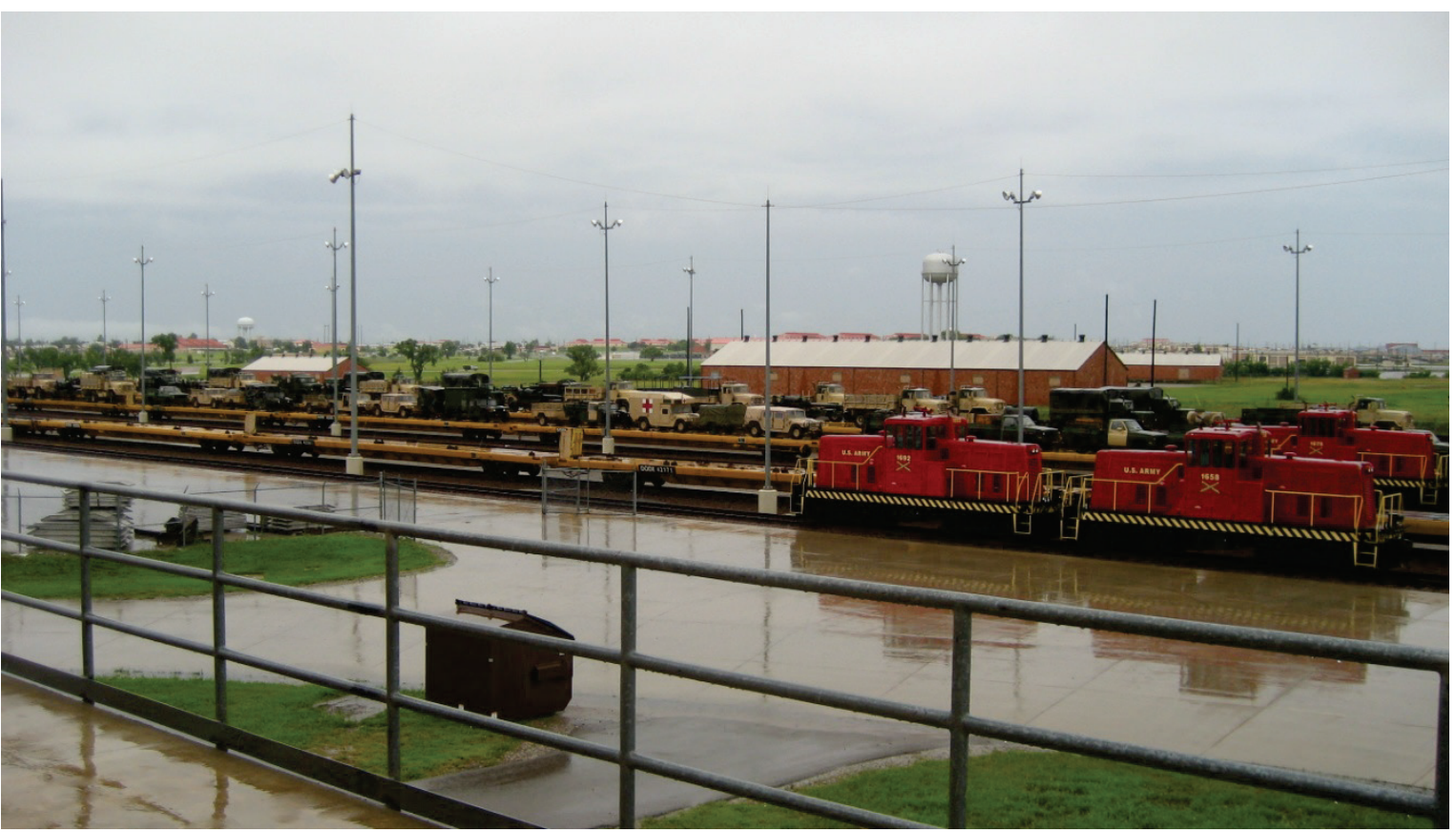


The U.S. Army Engineer Research and Development Center (ERDC) solves the nation's toughest engineering and environmental challenges. ERDC develops innovative solutions in civil and military engineering, geospatial sciences, water resources, and environmental sciences for the Army, the Department of Defense, civilian agencies, and our nation's public good. Find out more at www.erdc.usace.army.mil.

To search for other technical reports published by ERDC, visit the ERDC online library at https://erdclibrary.on.worldcat.org/discovery. 


\section{Electronic Railroad Inspection Database System for Military Facilities}

T. Jeremy Beasley, Anthony J. Falls, Chad A. Gartrell, and Lora L. Johnson

Geotechnical and Structures Laboratory

U.S. Army Engineer Research and Development Center

3909 Halls Ferry Road

Vicksburg, MS 39180-6199

Judy Reagan and Caleb Carter

GISinc

2100 Riverchase Center, Suite 105

Birmingham, AL 35244

Final report

Approved for public release; distribution is unlimited.

Prepared for Headquarters, Installation Management Command

G4 Public Works Division Facilities Management Branch

2405 Gun Shed

Fort Sam Houston, TX 78234-1223

Under Project Number 403398 


\section{Abstract}

The U.S. Army Engineer Research and Development Center (ERDC) executes inspection programs as part of the U.S. Army Transportation Infrastructure Inspection Program (ATIIP). These inspections, monitoring, and assessment programs include airfields, bridges, dams, railroads, waterfront facilities, and ranges. To date, the process for these inspection programs has been manually intensive, time consuming, and difficult to scale. The ERDC is bringing digital business and spatial data collection methods to its inspection program for the military's railroad infrastructure. By combining GPS and GIS technologies into a mobile data collection solution, added efficiency and data quality have been brought to the field inspection workflow. This modernization effort also results in streamlined data processing and reporting. These improved processes will lead to higher quality data, better analysis of the new richer data content, and better decisions made by the end-users and stakeholders.

DISCLAIMER: The contents of this report are not to be used for advertising, publication, or promotional purposes. Citation of trade names does not constitute an official endorsement or approval of the use of such commercial products. All product names and trademarks cited are the property of their respective owners. The findings of this report are not to be construed as an official Department of the Army position unless so designated by other authorized documents. 


\section{Contents}

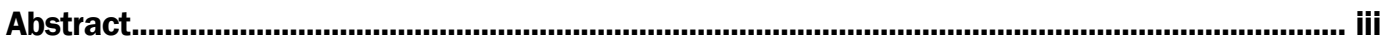

Figures and Tables............................................................................................................vi

Preface ................................................................................................................................................ vii

Executive Summary ...................................................................................................................................

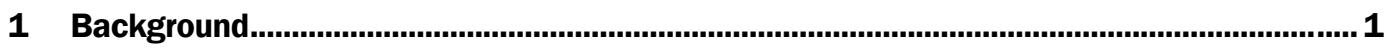

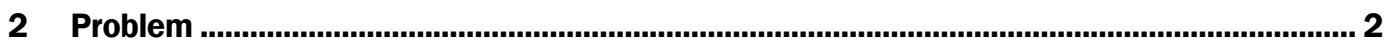

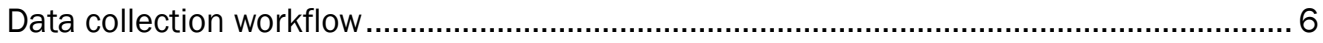

Evaluation of hardware and software components........................................................ 8

Decision drivers ......................................................................................................... 8

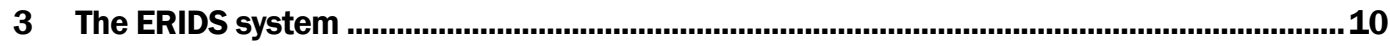

Application development process description:............................................................. 12

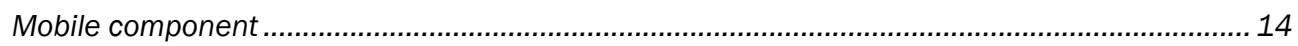

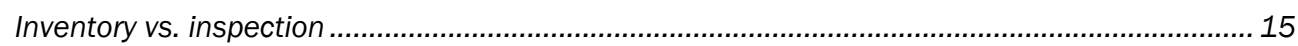

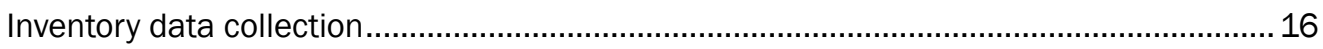

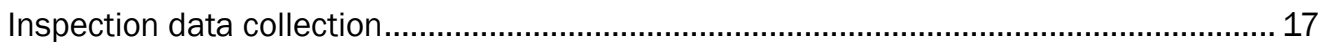

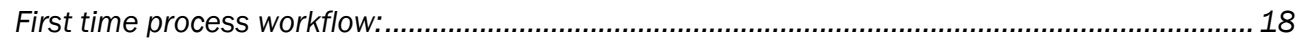

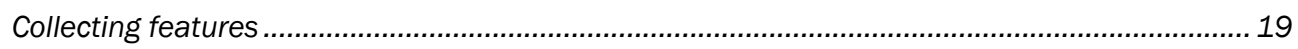

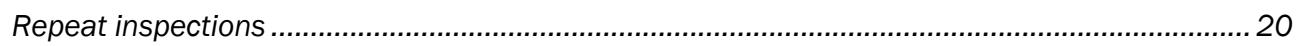

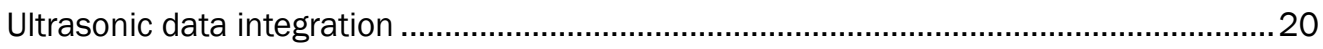

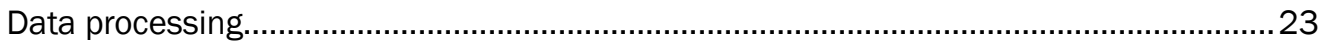

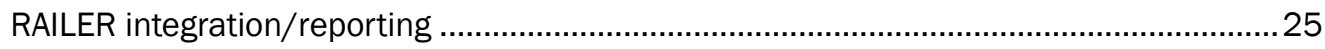

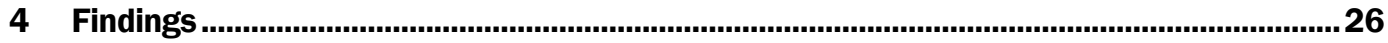

ERIDS data collection .............................................................................................. 26

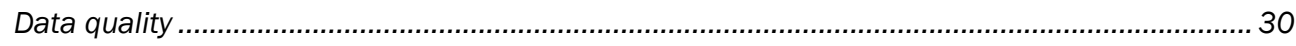

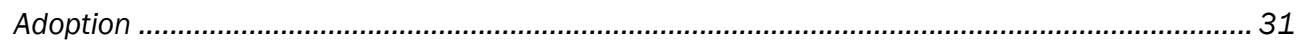

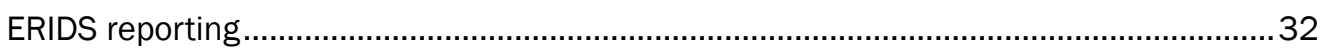

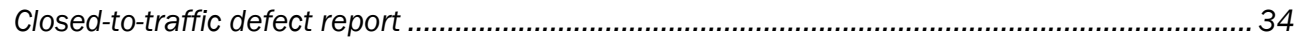

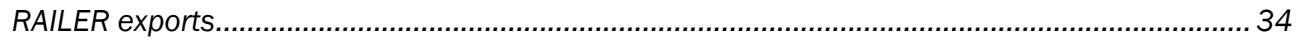

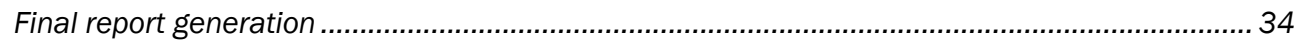

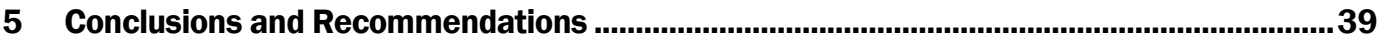

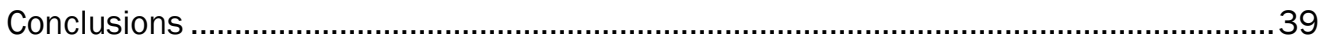

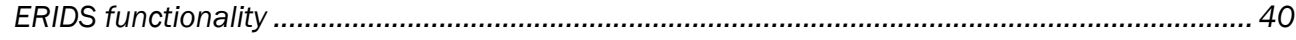

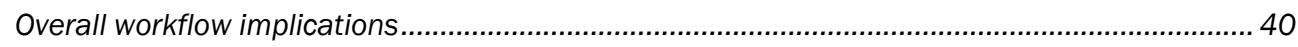

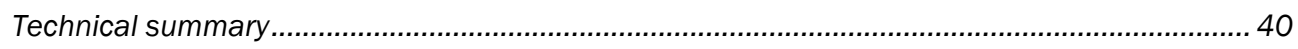

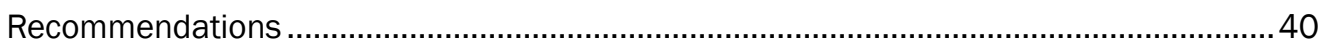




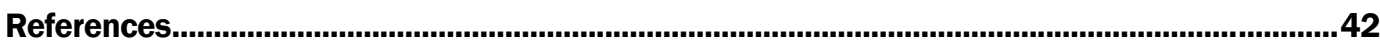

Appendix A - Adoption Survey Results .........................................................................

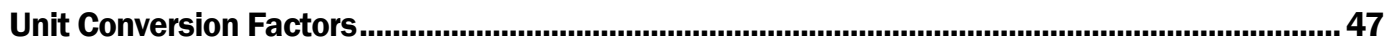

Report Documentation Page 


\section{Figures and Tables}

\section{Figures}

Figure 1. Inventory sheet and inspection form ......................................................................... 3

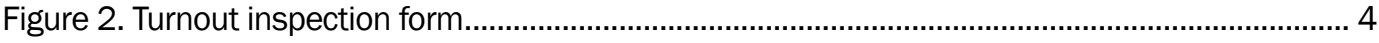

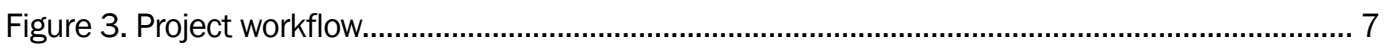

Figure 4. System architecture. ..................................................................................................... 14

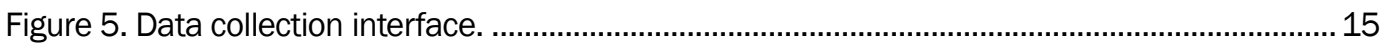

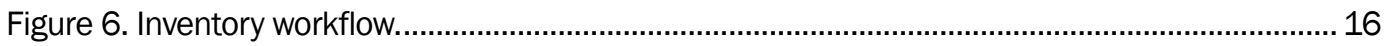

Figure 7. Inventory screenshot from handheld....................................................................... 16

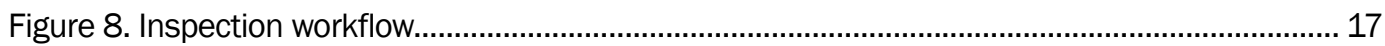

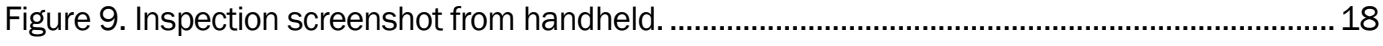

Figure 10. Handheld ultrasonic selection............................................................................... 21

Figure 11. Ultrasonic screenshot...................................................................................................2

Figure 12. Trimble positions main screen.................................................................................. 24

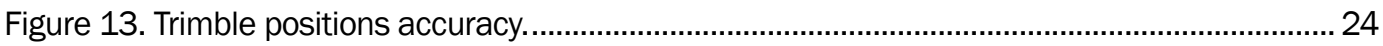

Figure 14. ERIDS data collection workflow. ......................................................................... 2 .

Figure 15. Screen shot of ERIDS main screen. ............................................................................. 28

Figure 16. Screen shot of ERIDS drain feature. ........................................................................ 28

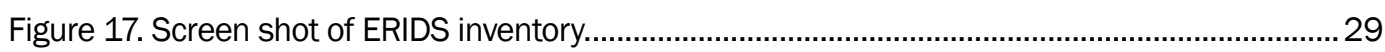

Figure 18. Screen shot of ERIDS inspection............................................................................... 29

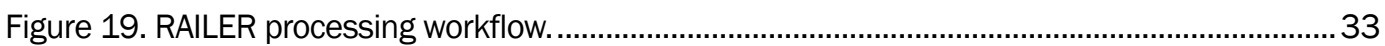

Figure 20. Map of Sierra Army Depot prior to ERIDS field implementation. ......................................37

Figure 21. Map of Sierra Army Depot after ERIDS data collection...................................................38

\section{Tables}

Table 1. List of Inspection steps identified in the requirements for custom ERIDS software............11

Table 2. List of commercial off-the-shelf components and custom hardware of the prototype ERIDS system. .................................................................................................... 12

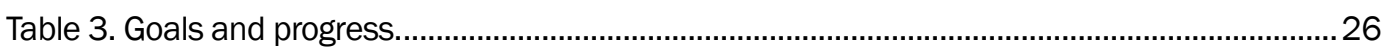

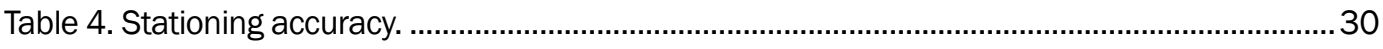

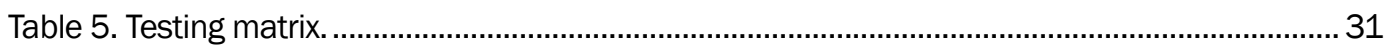

Table 6. Summary of inspector survey results. ………….................................................................

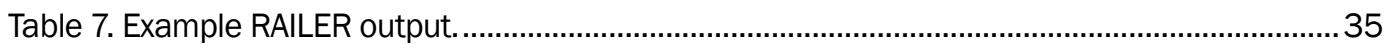

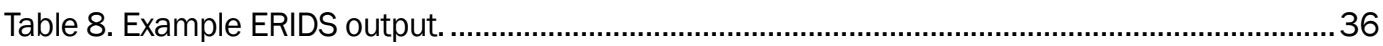




\section{Preface}

The tests and results described herein cover the first $1.5 \mathrm{yr}$ of development and initial deployment and testing.

The Electronic Railroad-Inspection Database System (ERIDS) project is a part of the Rail Inspection Program executed by the U.S. Army Engineer Research and Development Center (ERDC) and the U.S. Army Transportation Infrastructure Inspection Program (ATIIP). The project was funded by the Office of the Assistant Chief of Staff for Installation Management (OACSIM), under Project Number 403398.

This work was performed by the Airfields and Pavements Branch (GMA) of the Engineering Systems and Materials Division (GM), U.S. Army Engineer Research and Development Center, Geotechnical and Structures Laboratory (GSL). At the time of publication, Mr. Daniel Harder was Acting Chief, GMA; and Mr. Justin S. Strickler was Chief, GM. Mr. Charles W. Ertle II was Deputy Director of ERDC-GSL, and the Director was Mr. Bartley P. Durst.

COL Teresa A. Schlosser was Commander of ERDC, and Dr. David W. Pittman was Director.

The findings presented in this report are based upon efforts and evaluations conducted at ERDC and during a series of controlled test section experiments at the following sites: McAlester Army Ammunition Plant, Aberdeen Proving Ground, Sierra Army Depot, Fort Drum, Katterbach Kaserne, Baumhoulder Garrison, Graffenwoehr, Vilseck, and Kaiserslautern Army Depot. The principal investigators for this study were the authors of this report. Other GMA personnel who assisted in the inspection process included Mr. Michael Crawford, Mr. Donald Embry, and Mr. Matthew Norris. Mr. Ryan North of the Geotechnical Engineering and Geosciences Branch (GSG) was instrumental in helping identify the hardware that was necessary for the collection of the ERIDS data.

Recommended changes for improving this publication in content and/or format should be submitted on DA Form 2028 (Recommended Changes to Publications and Blank Forms) and forwarded to Headquarters, U.S. Army 
Corps of Engineers, ATTN: CECW-EWS, Kingman Building, Room 321, 7701 Telegraph Road, Alexandria, VA 22315. 


\section{Executive Summary}

This report describes the planning, application development and results of Phase 1 of the ERIDS project. This technology will give the U.S. Army and other Armed Forces the ability to effectively and efficiently maintain railroad track inspection data. The functional objectives of this project were to:

- Automate and improve data collection techniques

- Enhance report generation and analysis methods

- Implement a geo-enabled enterprise integration and data management solution

The project included a new mobile data collection/inspection application and the ability to export the data to a format that can be consumed by the existing RAILER software for use in reporting.

The ERDC executes inspection programs as part of the U.S. Army Transportation Infrastructure Inspection Program (ATIIP). These inspection, monitoring, and assessment programs include airfields, bridges, dams, railroads, waterfront facilities, and ranges. To date, the process for these inspection programs has been manually intensive, time consuming and difficult to scale. The ERDC is bringing digital business and spatial data collection methods to its inspection program for the military's railroad infrastructure. By combining GPS and GIS technologies into a mobile data collection solution, added efficiency and data quality have been brought to the field inspection workflow. This modernization effort also results in streamlined data processing and reporting. These improved processes will lead to higher-quality data, better analysis of the new richer data content and better decisions made by the end-users and stakeholders.

The tests types, results, and recommendations described herein cover the first $1.5 \mathrm{yr}$ of development and initial deployment and testing. 


\section{Background}

As a large and technically advanced organization, the U.S. Army faces continual challenges with the management of critical infrastructure. These challenges include improving data collection, quantifying the quality of the collected data, and analyzing data and transforming them into information upon which infrastructure managers and end-users can base informed decisions. Interdisciplinary teams of the U.S. Army Engineer Research and Development Center (ERDC) manage and execute infrastructureinspection programs as part of the U.S. Army Transportation Infrastructure Program, under the auspices of the U.S. Army Installation Management Command (IMCOM). Within these programs, ERDC team members collect and manage huge datasets from inspection, monitoring, and assessment of airfields, bridges, dams, railroads, waterfront facilities, and ranges.

Previous research has demonstrated that the process of assessing the condition of a subset of railroad elements-specifically ballast and subgradecan benefit from the use of ground-penetrating radar or other non-invasive tools, and that the process is enhanced by use of global-positioning system (GPS) data and digital video (Selig et al. 2006). This report focuses on automating inspection of and reporting on Army rail systems on military bases using best-available tools in an integrated system of hardware and software combined with customized software. 


\section{Problem}

The Department of Defense (DoD) railroad system is a critical asset both for peacetime facility functions and for mobilization in time of national need. The Army maintains over 1,500 miles of railroad track throughout the United States and overseas, serving a vital role for the DoD. These military tracks have unique management and maintenance requirements due to lower speeds, frequency of use, and the nature of DoD cargo. To ensure that military cargoes are transported safely and to protect a major national investment, military tracks must be inspected periodically and monitored for change. Given the aging nature of DoD rail infrastructure, track maintenance requires best use of available data for cost-effective decision making.

To manage and maintain these critical infrastructure assets, the Army has implemented a program of inventories and inspections specific to railroads and is contained in UFC 4-860-03 (Headquarters, Departments of the Army, the Navy, and the Air Force 2008). On behalf of IMCOM, ERDC manages and performs railroad inspections on 70 military bases worldwide. Inspection of railroad track systems involves several datacollection steps. During inspection, the note-taker of the inspection crew fills in two different pre-printed sheets. The first sheet (Figure 1) is a trackinspection form, which provides spaces to record track name and information and location of inventory items and defects. General track characteristics, such as tie size and ballast type, are also recorded. The second sheet (Figure 2) is a form used to record measurements of the gauge and components of the turnout, including condition of components, condition of switch ties, and any defects found in any of these parts. 
Figure 1. Inventory sheet and inspection form.

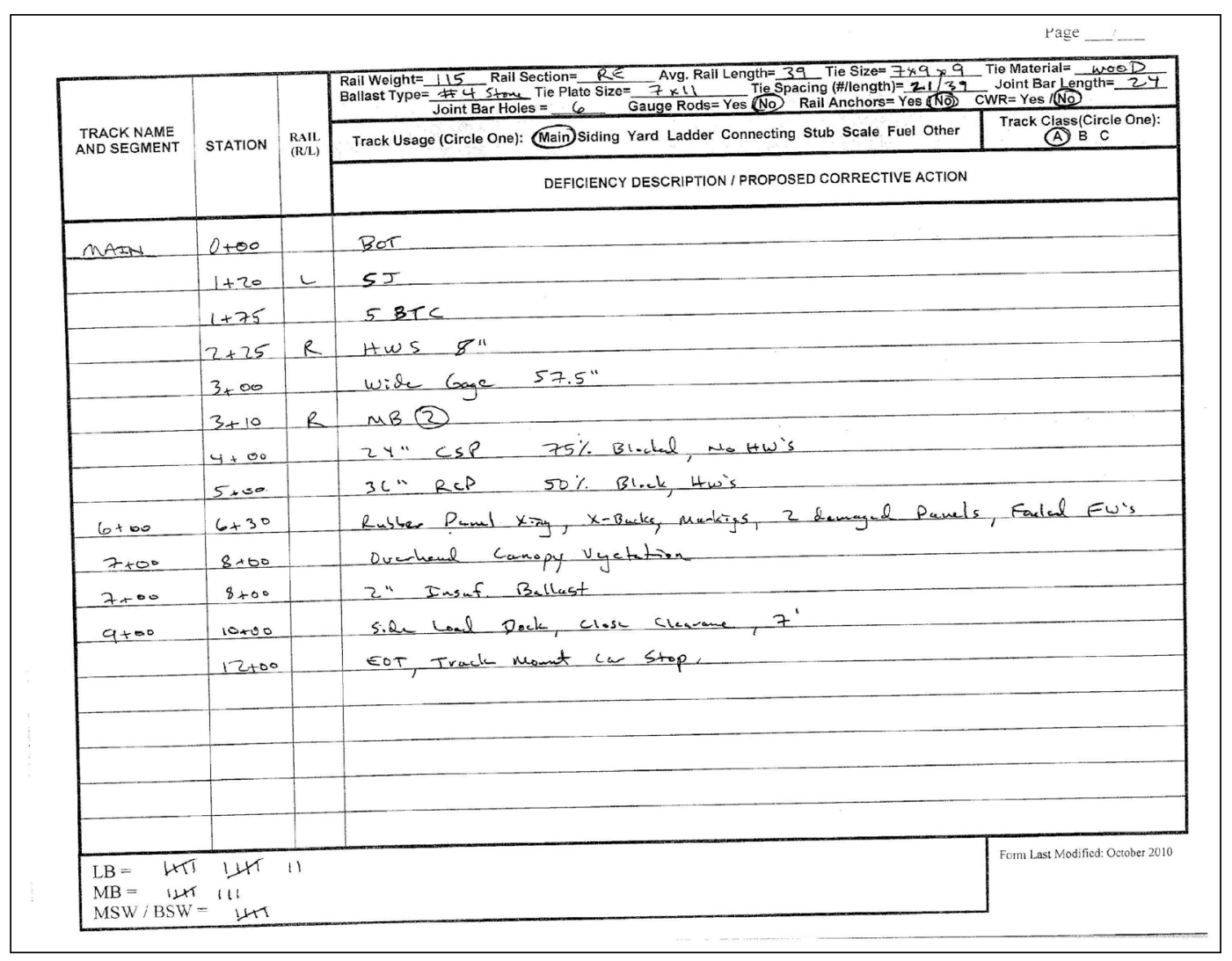


Figure 2. Turnout inspection form.

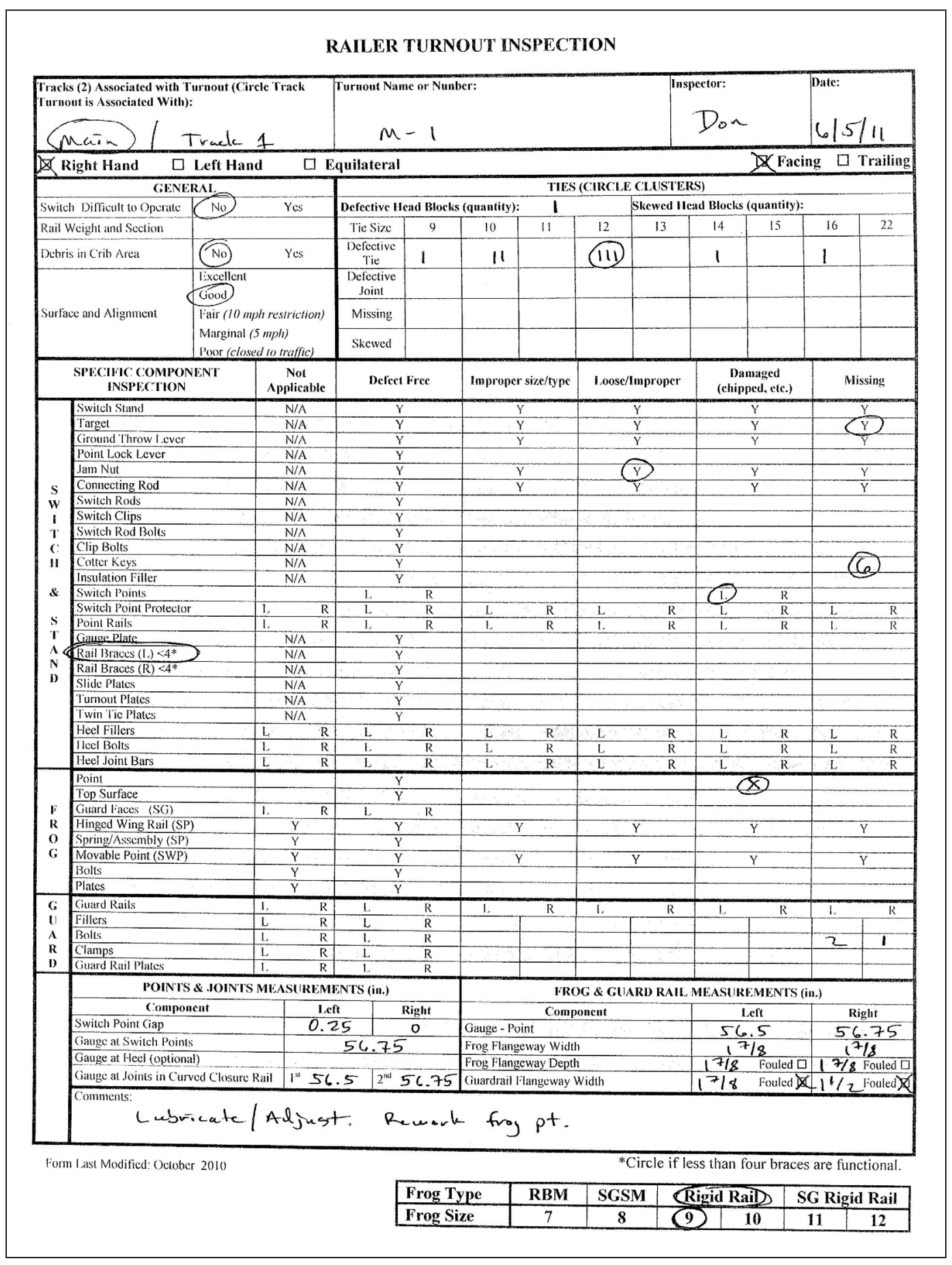

In current practice, the inspection teams complete these forms by hand in the field. Data from the forms are then entered manually into two condition-assessment and maintenance-planning software programs developed at the ERDC: RAILER and its companion, the RAILER Remote Entry Database (RED) (Grussing 2009). RAILER and RAILER RED have 
few GIS capabilities other than empty database queries and are limited to storing data in a Microsoft Access-format database template (file extension.mdb). These limitations reduce the efficiency of the inspection process. To transition from RAILER RED to a platform that takes advantage of recent advancements in GPS and GIS technologies, the inspection system must include a full geodatabase that can be accessed and edited via RAILER and common GIS software products (e.g., ESRI ArcGIS). Further, the new platform must be able to perform the same automated inspection tasks as RAILER and RAILER RED.

Written records from the field inspection can be critically important, especially to resolve confusing issues during data entry. From a liability standpoint, these records must be kept on file for five years. However, the use of the RAILER RED program, in conjunction with a tablet PC for which it was designed, has proven to be cumbersome and not inspection-team friendly. The program requires many steps, tabs, and fill-in information to capture the data required. Tablet PCs are not carried conveniently in the field for long distances, are typically not ruggedized for outdoor use, and their screens are not easily visible in glaring sunlight.

Although the current process is partly automated, it has proven to be manually intensive, time consuming, and difficult to scale. The current practice involves walking miles of track while rolling a wheel and recording data on paper data sheets or a tablet PC. Time-consuming data recording is followed by post-field data entry into separate disconnected databases for each military facility. Current practice also introduces potential transcription errors that cause delays in analysis, interpretation, and reporting. The labor-intensive aspects of the current process are the rate-limiting step in inspections and may cause rail-system managers to miss critical time windows for lower-cost maintenance actions.

The current mapping process is inaccurate, time consuming, and generic. Features are created by simply digitizing railroad centerlines and calibration points on top of various sources of imagery. This raw digitization leads to inaccuracies in the location of inventory and inspection items. The current process is time consuming, because every track centerline and calibration point has to be entered by hand in the office after returning from an inspection. For larger installations, this can take up to two weeks to complete a drawing. The current mapping process is generic in that it 
provides only the railroad centerline and turnout locations and is limited in the information it can provide to the map reader.

\section{Data collection workflow}

The data collection workflow was documented with direct input and collaboration with end-users and stakeholders (Figure 3). 
Figure 3. Project workflow.

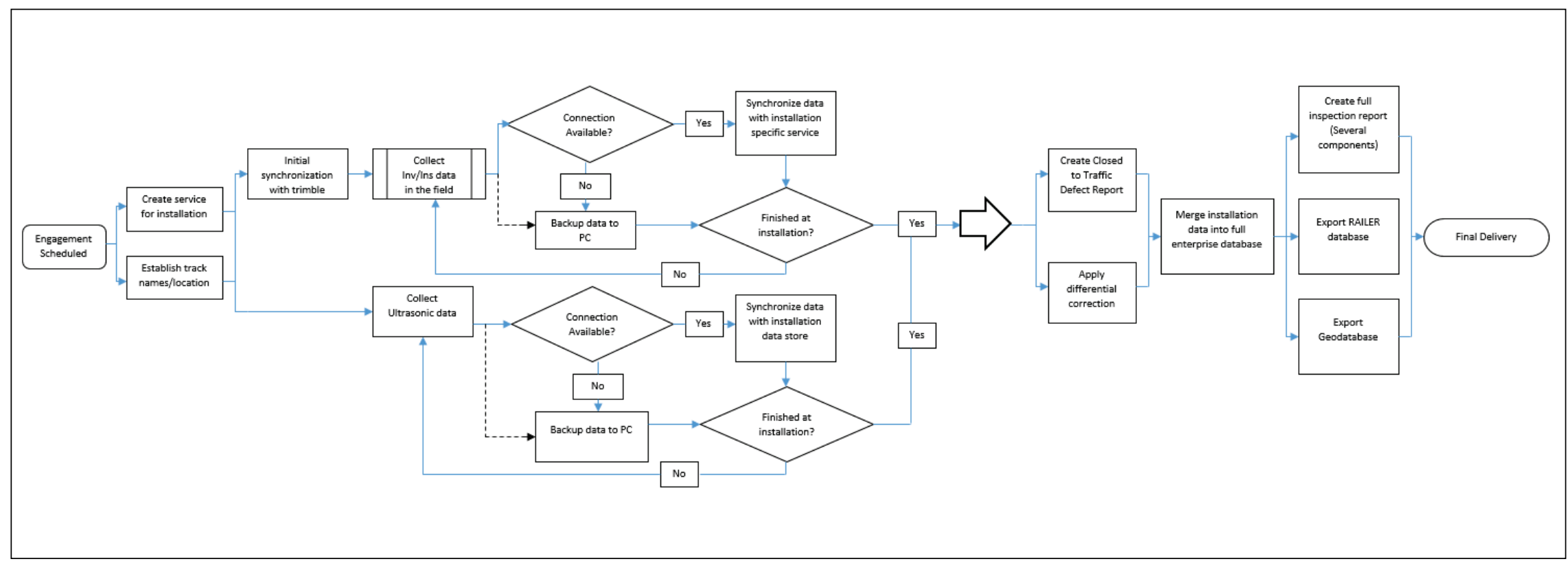


During the requirements and the design steps, it was determined that the data model would need to facilitate workflow as opposed to simply support an application or data warehousing. Considerations for creating a data model included:

- Facilitate the simplest collection workflow possible

- Be able to export data to a RAILER database

- Consider existing DoD data standards (SDSFIE)

- Consider eventual integration with Army Mapper

- Accommodate ALL installations

Naming Conventions

- Inventory

- Inspection

\section{Evaluation of hardware and software components}

Requirements gathering revealed the need for mobility, electronic (digital) data collection, disconnected editing, and enhanced accuracy of GPS data. COTS software products were available to meet the fundamental functions required. Hardware components of ERIDS were identified from best practices in other digital data-collection and database-building systems. The primary component of the ERIDS hardware is a Trimble GeoXH ${ }^{\circledR}$ handheld unit loaded with a custom application built on ESRI ArcGIS Mobile and Trimble Positions software. This combination allows the user to enter railroad inspection data in a menu-driven touch-screen environment.

\section{Decision drivers}

The major decision drivers for this project were to:

- Eliminate field collection data sheets; collect data digitally.

- Reduce data collection time and staff requirements for railroad inspections by $30 \%$, improve data quality, and support new sensing platforms and data.

- Reduce time and cost to generate inspection reports by 50\%, improve consistency and quality in the report content, and provide new capabilities to spatially analyze and visualize the information.

- Provide efficiencies in data management through an enterprise database solution, simplified management dashboards for visualization and 
analysis of the data, and integration with the Army enterprise geographic information system, Army Mapper.

- Integration of ultrasonic truck data with the visual inspection team data. 


\section{The ERIDS system}

Populating forms electronically has become a commonplace and trusted form of recording data. Advantages of using automated forms and form population include: no chance of illegible notes, more precise and efficient form population, no paper required, less material to carry and keep organized in the field, decreased chance of data-entry error and duplication, and near-real-time delivery of critical inspection results-such as track segments with close-to-traffic defects-delivered to the installation.

ERIDS software requires best use of existing platforms coupled with development of new software to integrate sensing technologies into operations and to provide capabilities to support new sensing methods and enterprise integration.

The software divides the inventory and inspection process into 182 individual items in categories that include synchronization ( 5 items), inspection set-up (5), and multiple sub-categories each with multiple entry items for the inventory (11 sub-categories) and inspection (13 sub-categories) requirements of the ERIDS process. Table 1 lists the categories and subcategories of actions addressed by the custom software and the number of individual items included in each category or sub-category. As an example, the six specific data-entry items included in the category "Inspection," subcategory "General" are (1) identify track, (2) identify segment, (3) enter deficiency description, (4) enter location of deficiency, (5) capture photograph, and (6) comment on inspection. All of the actions outlined in Table 1 are taken using the hardware and software listed in Table 2. Geographic Information Services Inc. is developing the software under contract to the ERDC ERIDS team. 
Table 1. List of Inspection steps identified in the requirements for custom ERIDS software.

\begin{tabular}{|c|c|c|}
\hline Category & Sub-category & Number of items or steps \\
\hline Synchronization & - & 5 \\
\hline Inspection set-up & - & 5 \\
\hline \multirow[t]{11}{*}{ Inventory } & Track characteristics & 17 \\
\hline & Track segment & 5 \\
\hline & Appliances & 2 \\
\hline & Turnouts & 7 \\
\hline & Curves & 3 \\
\hline & Bridges & 4 \\
\hline & Grades & 2 \\
\hline & Grade crossings & 8 \\
\hline & Rail crossings & 5 \\
\hline & Restrictions & 8 \\
\hline & Drainage & 7 \\
\hline \multirow[t]{13}{*}{ Inspection } & General & 6 \\
\hline & Ties & 4 \\
\hline & Fasteners & 3 \\
\hline & Rail and ballast & 4 \\
\hline & Appliances, rail crossings, and drainage & 4 \\
\hline & Grade crossings & 11 \\
\hline & Track geometry deviation & 5 \\
\hline & Turnouts, general information & 9 \\
\hline & Turnouts, switch and stand & 30 \\
\hline & Turnouts, frog & 9 \\
\hline & Turnouts, guard & 10 \\
\hline & Turnouts, measurements & 8 \\
\hline & Impaired (segment cannot be inspected) & 1 \\
\hline
\end{tabular}


Table 2. List of commercial off-the-shelf components and custom hardware of the prototype ERIDS system.

\begin{tabular}{|l|l|l|}
\hline \multicolumn{1}{|c|}{ Component } & Manufacturer & \multicolumn{1}{c|}{ Model } \\
\hline GIS-grade GPS unit & Trimble & GeoXH 6000 \\
\hline GPS antenna & Trimble & Zephyr 2 \\
\hline Vertical pole for Zephyr 2 & Trimble & Range pole \\
\hline Equipment case for GeoXH, Zephyr 2, accessories & Trimble & -- \\
\hline Software for GPS range data & Trimble & GPSCorrect for ArcPad \\
\hline Software for post-processing GPS data & Trimble & GPSAnalyst for ArcGIS \\
\hline GIS software & ESRI & ArcGIS \\
\hline Extended warranty for GeoXH & Trimble & - \\
\hline Bracket and cable for connecting GeoXH and Zephyr 2 & Trimble & - \\
\hline
\end{tabular}

\section{Application development process description:}

The application development phases are:

- Planning \& Analysis Phase - The first phase is devoted to information gathering, review and immersion of project staff to confirm requirements and target environments prior to the design phase.

- Design Phase - This phase starts with the refinements to functional use cases in the planning and analysis phase and transforms them into a technical design and the development workflows that serve as the application blueprint. The outcome of this phase is the technical design and user interface mock-ups.

- Development Phase - This phase begins as developers translate refined workflows into application modules. Development of the application components will occur based on the refined requirements and design. A unique feature of the approach is the use of in-progress development reviews with the team and stakeholders to provide checkpoints during the development phase. This allows the stakeholders to review the required functionality as it is developed.

- Testing Phase - Once development is complete, the code is checked into the source control system, and compiled and deployed into an integration environment. Functional testing is performed by the internal testing team and any issues are reported back to the development team using the information. After functional testing is completed, the application is deployed to the ERDC environment for systems integration testing. Once integration testing is complete, 
functional acceptance testing (FAT) is performed in the TEST environment by stakeholders.

- Implementation Phase - Upon completion of FAT and approval of the release, GISi provides technical expertise to the ERDC IT team to support final integration of the accepted code base into the production environment, including help documentation and release notes.

System Architecture - The rail inspection solution is composed of several components including the following:

- Data Collection in the field using a mobile platform.

- Storage and Maintenance of inspection data from multiple inspections at several different facilities.

- Data Analysis and Reporting tools to support the delivery of inspection reports, as well as data delivery to the installations after inspection.

Figure 4 shows a graphic representation of the system architecture that will support the above solution. There are four major components of this architecture:

- ArcGIS Server 10, $\mathrm{SP}_{3}$ - This server hosts the Map services used for synchronizing data between the field devices and the geodatabase. It will also host any services required to support downstream data analysis and reporting.

- ArcGIS Desktop 10, $\mathrm{SP}_{3}$ - The desktop software is used for authoring map documents, as well as the services that run on the ArcGIS Server. The desktop will also support post-processing workflows including differential correction of GPS data and related data processing.

- Trimble GeoXH 6000 - The hand-held device runs a custom data collection application built on ArcGIS Mobile and Trimble Positions software. This device will run in a disconnected mode in the field and will synchronize when a network is available back to the ArcGIS Server.

- Enterprise Geodatabase

○ SQL Server 2008 R2

- ArcSDE 10, $\mathrm{SP}_{3}$

- There is currently one database in this environment, storing all of the inspection data from multiple inspections of each installation.

Depending on the scale of the application in the future, there may be additional databases to support the lookup tables for data collection, 
field geodatabases to segregate data collection workflows from the enterprise data store, etc.; the design facilitates this option.

Figure 4. System architecture.

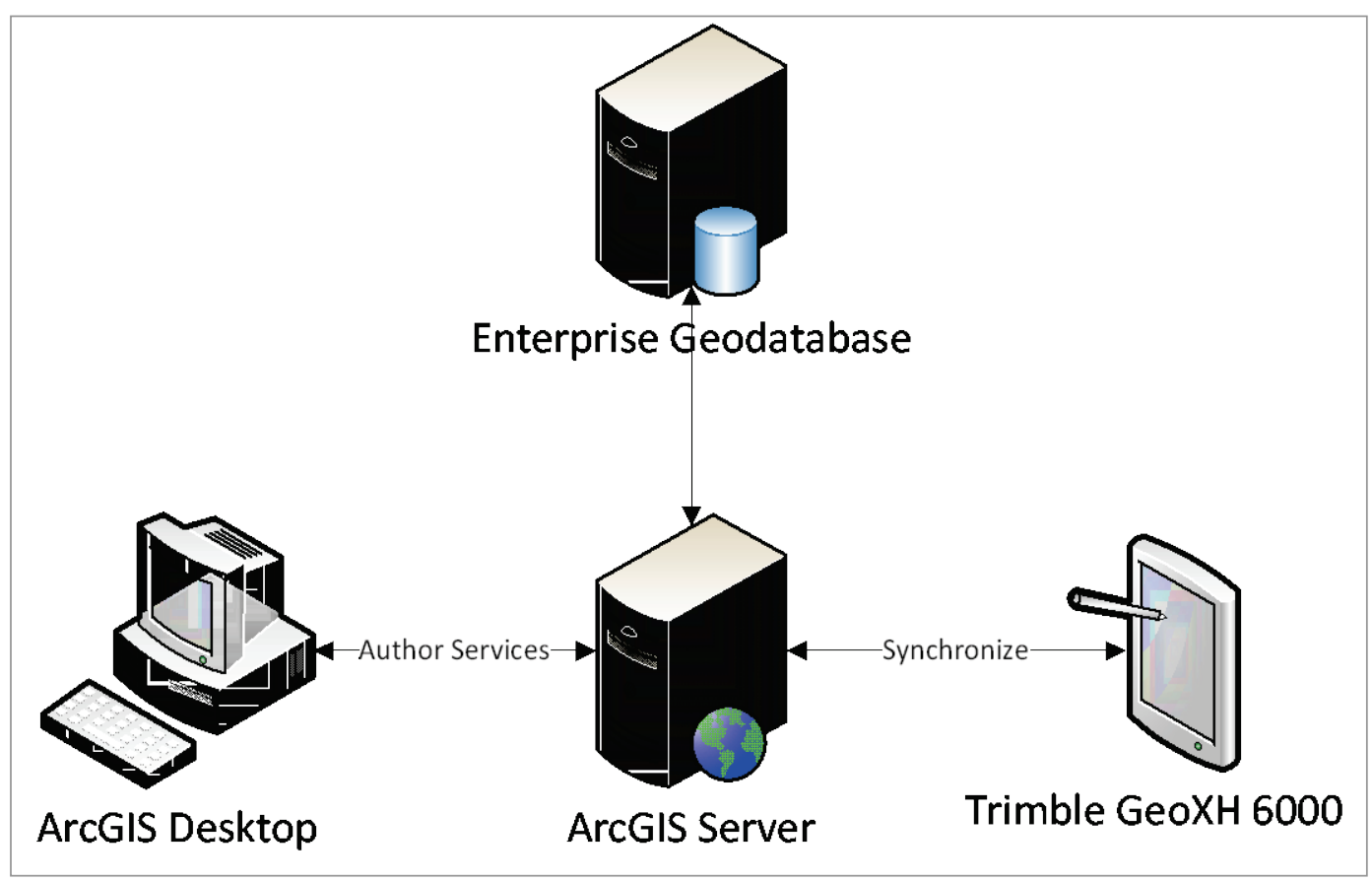

\section{Mobile component}

ArcPad was identified as the early mobile component due to the availability of GPS Correct, which enabled users to differentially correct collected features, thus improving spatial accuracy (a major driver for ERDC). As requirements were gathered and additional investigation into ArcPad revealed its limitations (customization limited, poor user interface, required GIS knowledge for use), ArcGIS Mobile was favored for the mobile component.

ArcGIS mobile is a customizable, menu-driven, business application focus, compatible with Trimble hardware and capable of simultaneous multi-feature collection. Coupled with Trimble Positions, an ArcGIS Mobile solution enabled differential correction.

The final mobile component is SQL Server that allows synchronization with a compact database on a mobile device for non-spatial (business-related) data. 
When designing the application, an intuitive UI was very important since it would have to be adopted by the current pool of rail inspectors. The outcome was a series of work flows in which each mobile screen page emulates a digital version of the data collection options (Figure 5) seen on the paper collection forms that were currently being used.

Figure 5. Data collection interface.

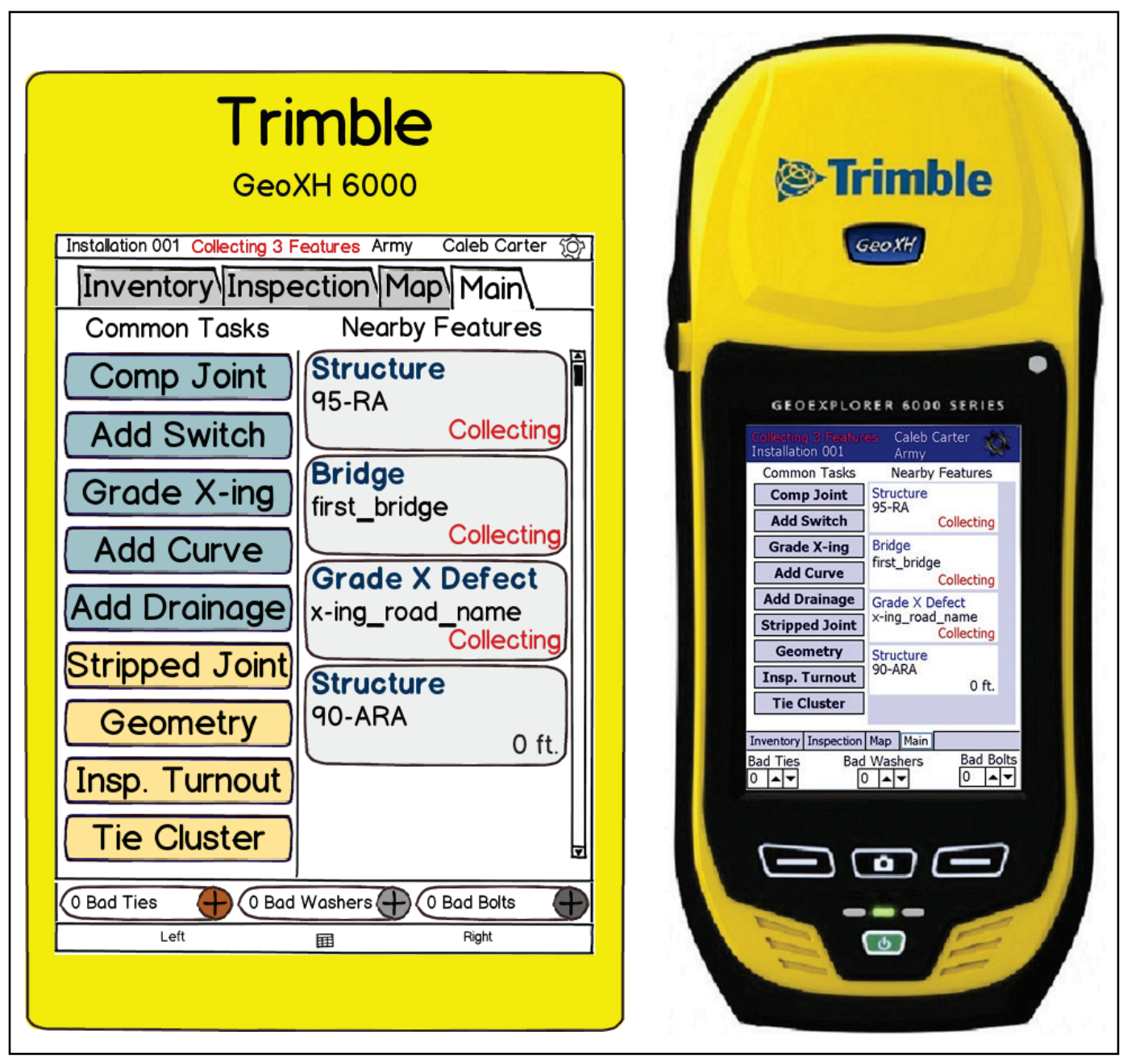

\section{Inventory vs. inspection}

Inventory refers to the physical existence of tracks and track components. Inspection is the current assessment of the condition of tracks and track components. 


\section{Inventory data collection}

The inventory workflow steps through the process of data collection/ development and drives to the outcome are shown in Figure 6.

Figure 6. Inventory workflow.

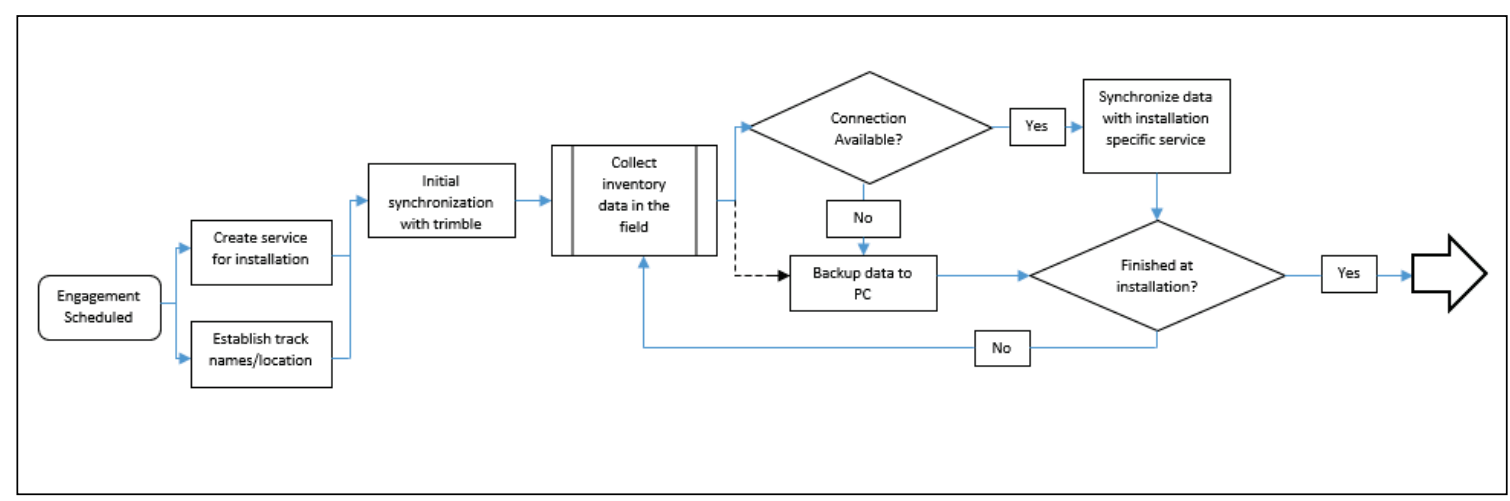

Below is a screenshot of the inventory items (Figure 7) that can be collected and maintained using the mobile application.

Figure 7. Inventory screenshot from handheld.

\begin{tabular}{|c|c|c|}
\hline \multicolumn{2}{|c|}{$\begin{array}{l}\text { Collecting } 0 \text { Features } \\
\text { Current Track: Track1 }\end{array}$} & \multirow{2}{*}{ 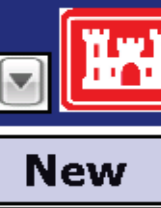 } \\
\hline TrackStructure & Edit & \\
\hline \multicolumn{2}{|l|}{ Appliance } & Add \\
\hline \multicolumn{2}{|l|}{ Turnout } & Add \\
\hline \multicolumn{2}{|l|}{ Rail X-ing } & Add \\
\hline Curve & Edit & New \\
\hline Bridge & Edit: & New \\
\hline Grade & Edit & New \\
\hline Grade $X$-ing & Edit & New \\
\hline Restriction & Edit & New \\
\hline \multicolumn{2}{|l|}{ Drainage } & Add \\
\hline
\end{tabular}




\section{Inspection data collection}

The inspection workflow steps through process of data development and the outcome are shown in Figure 8.

Figure 8. Inspection workflow.

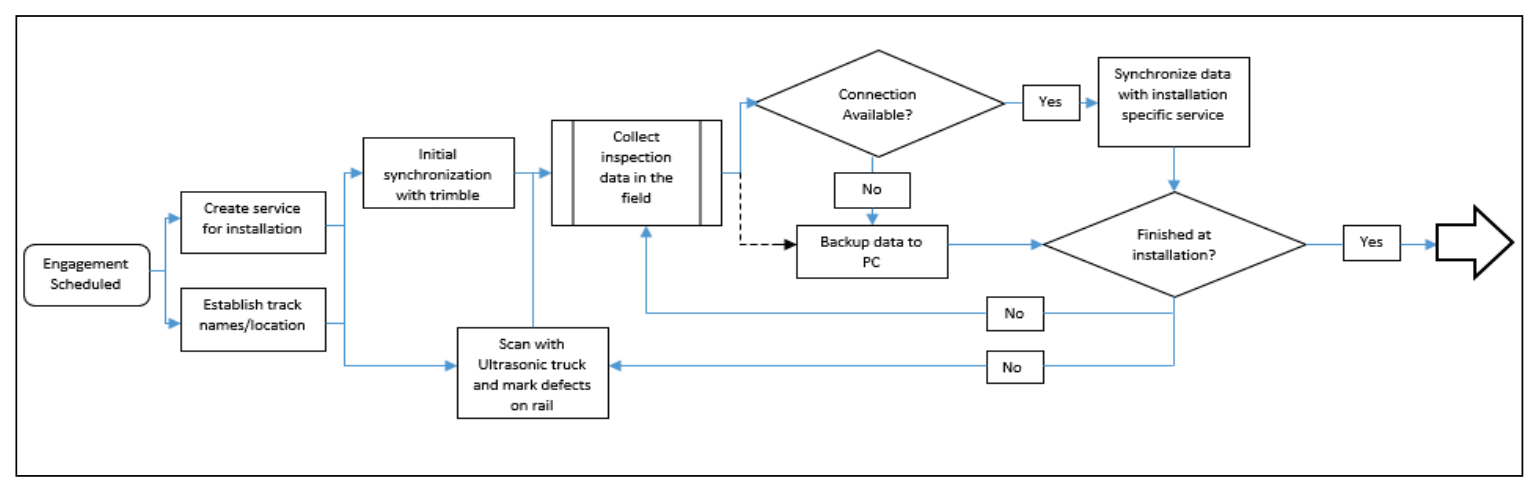

Below is a screenshot (Figure 9) of inspection items that can be collected and maintained using the mobile application. 
Figure 9. Inspection screenshot from handheld.

\begin{tabular}{|c|c|c|}
\hline \multicolumn{2}{|c|}{$\begin{array}{l}\text { Collecting } 0 \text { Features } \\
\text { Current Track: Track1 }\end{array}$} & 包 \\
\hline \multicolumn{2}{|l|}{ Rail Defect } & Add \\
\hline \multicolumn{2}{|l|}{ FOTM Defect } & Add \\
\hline Ballast Defect & Edit & New \\
\hline Inspection Impaired & Edit & New \\
\hline \multicolumn{2}{|l|}{ Appliance Defect } & Add \\
\hline \multicolumn{2}{|l|}{ Drainage Defect } & Add \\
\hline \multicolumn{2}{|l|}{ Turnout Defect } & Add \\
\hline \multicolumn{2}{|l|}{ Tie Defect } & Add \\
\hline Manual Track Geom. & Edit & New \\
\hline \multicolumn{2}{|l|}{ Rail X Defect } & Add \\
\hline \multicolumn{2}{|l|}{ Grade X Defect } & Add \\
\hline \multicolumn{3}{|c|}{ Main Inventory Inspection Sync } \\
\hline
\end{tabular}

\section{First time process workflow:}

Before going out in the field with the Trimble device, the user will need to set up some information about the Project, Device and Sessions. Using ESRI's ArcMap software and the Trimble Positions Office tools, the user executes the following:

- Identifies which mobile map service is to be used to sync the data.

- Defines which layers the Trimble SDK will be responsible for collecting (Trimble Points). This layer will get tagged with the ID of the device that was used to collect the data. The Trimble Positions SDK does not allow collection of multiple features at once, so all track information is collected in the Trimble Points layer.

- Names device, ties it to an ID and assigns to a profile, which defines what region of the world data collection occurs and which should be used.

- Selects a geodatabase in which the Trimble Sessions feature class will be created. 
Once the project is setup and saved to the database, an .sdf file is created and put onto the device. This file tells the device which layers to collect in the field.

Each time a user starts the data collection application on the Trimble device, the user will be required to enter several pieces of information regarding the details of the engagement as well as the task being performed:

- Name -

- Installation - (drop down menu)

- Military Branch - (filled in for the user)

- Inspection Date - (auto-populated)

- Task - (visual or ultrasonic)

- First Inspection - (yes/no)

\section{Collecting features}

When the inspector clicks "Start Track," a data form will be presented to enter the specific attributes for the track. This will serve as an example of how data forms are handled in general. Aside from the specifics of the data fields for each type of rail feature in the system, the data forms are generally handled the same. When the user starts collecting a new feature, the user is presented with a full screen form that requires entering all of the data needed for the feature being created. In some cases, all data will fit on a single screen, whereas in other cases a multipage form may be required, as in the track example.

Starting at the top, the form has a title indicating the action being taken -"new" in this case; later, "edit" will appear -- as well as the feature type ("Track Structure"). There are controls to perform the following tasks:

- Close the form

- Capture image using the onboard camera (camera icon at the bottom of the form)

- Add a comment (comment bubble icon next to the camera)

- Navigate to the next or previous step. Note that on the first page of the form there is a "Next" button to go to page 2. On the second page of the form there is a "Back" button to return to page 1, as well as a "Start" button to save the attribute data that is entered and begin collecting the geometry for the item. 


\section{Repeat inspections}

A repeat inspection begins with the GIS Administrator creating a new inspection date for a previously inspected installation. The field inspector begins the repeat inspection by selecting the track to inspect from the dropdown menu at the top of the screen. The inspector will not make changes to inventory items unless quantities have changed since the last inspection. The inspector then proceeds down the track, beginning at the zero end of the track that was established on the first inspection. The inspector is not only concerned about current defects, but is also aware of past defects from prior inspections. Using the "Main" screen, the inspector can use the on-screen map as a reference for finding past defects and inventory items if necessary. The inspector can then select an inspection and/or inventory item with the stylus for editing or make comments about changes since the last inspection. Once the inspector has completed the evaluation of a track, he or she simply moves on to the next track, selecting the track to be inspected from the drop down menu at the top of the screen.

\section{Ultrasonic data integration}

The data collection application has the ability to integrate ultrasonic data during the inspection process (Figure 10). In the case that the inspector is performing an ultrasonic scan, the task is specific to finding internal rail defects. To this end, the "Task" selection is used when starting the application so that the Common Tasks list can be customized accordingly. 
Figure 10. Handheld ultrasonic selection.

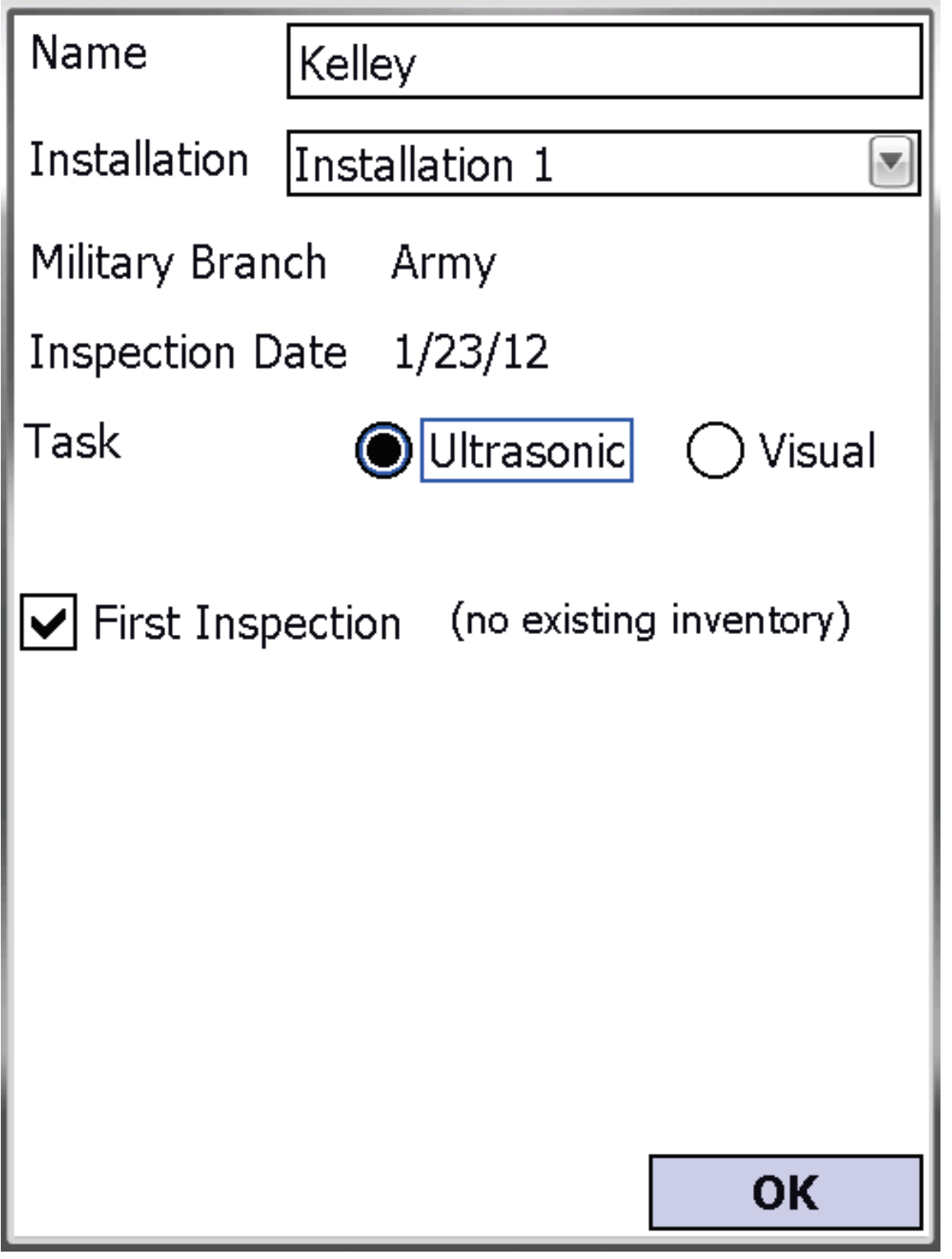


The following mockup (Figure 11) shows an example of what that list might look like.

Figure 11. Ultrasonic screenshot.

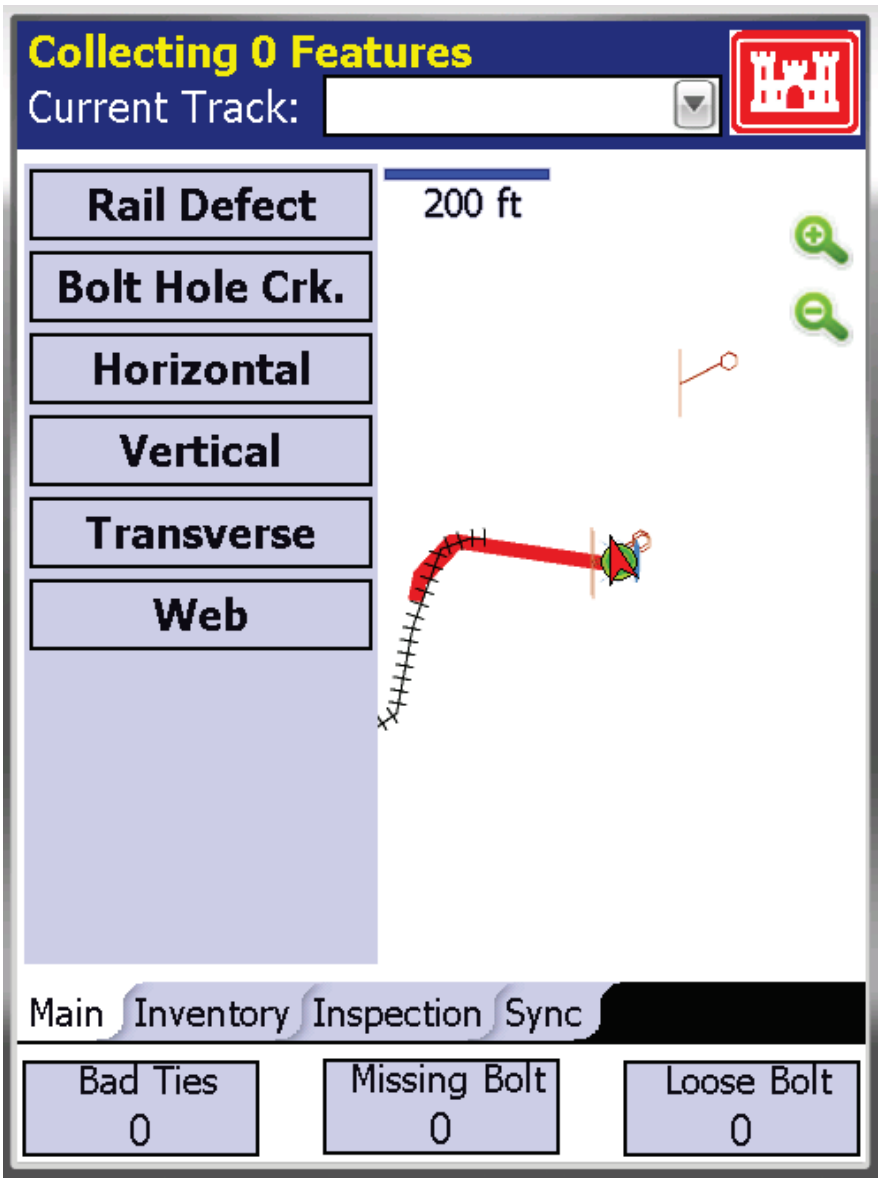

It also includes a nearby head web separation internal rail defect recorded from a previous inspection. When the ultrasonic team comes upon a previously recorded internal rail defect such as this, the team will do one of three things:

- If the defect is no longer there, delete the record.

- If the defect is there and has changed (for instance, gotten worse), edit the record accordingly.

- If the defect is there and remains unchanged, then leave the record as is.

As part of the overall ERIDS development effort, fundamental modifications to the ultrasonic truck data collection and export capabilities were 
necessary. Software for the ultrasonic truck was updated to address the following items:

- Implement yearly access database to store defect information from detector car with the following fields:

- Key, TrackName, Defect, Latitude, Longitude, Rail, Length

- Density, Quantity, Condition Level, Comments, Inspector, Date

- Implement table lookup and add GUI collection for following fields:

- Rail, DetRail (defect type) and Condition Level

- Unique KEY field for Database (GUID)

- Add and collect the following information from operator:

○ Track Name, Length, Density, Quantity, Comments

- Adjust date, allow operator to set date at startup and utilize

\section{Data processing}

Once the data collection is completed and synchronized back into the enterprise database. The first task is to list out all of the "closed-to-traffic" defects. To do this, a stored procedure is run that parses through all of the data looking for tracks that have exceeded the maximum number of allowed defects and must therefore be closed. This report is then printed and sent to the team responsible for maintaining the track.

Twenty-four hours after the data collection is finished, the GPS tower data is available to use for post-processing. The first task is to open an MXD containing all of the data layers using ESRI's ArcMap desktop software. Pan to the collection area in the map and enable the Trimble Extension. Open the Trimble Positions Office window to see all of the Trimble sessions that need differential corrections (Figure 12). 
Figure 12. Trimble positions main screen.

\begin{tabular}{|c|c|c|c|}
\hline \multicolumn{4}{|c|}{ Intrbic Poritons Office } \\
\hline \multicolumn{2}{|l|}{ Sentions: } & \multicolumn{2}{|c|}{ Qumort pxicot: rsintocotion } \\
\hline \multicolumn{4}{|c|}{ Drag a coimn header here to goup by tha coiven. } \\
\hline Devico & Time & r & Stahe \\
\hline Dence 1 & $7 / 29 / 20127.43 \mathrm{PM}$ & & Wating for Coriection \\
\hline Device 1 & $7 / 29 / 20121215 \mathrm{PM}$ & & Wating For Conection \\
\hline Device I & 7/28/201211-22 AM & & Wating For Coriection \\
\hline Dence 1 & $7 / 12 / 20129.11 \mathrm{AM}$ & & Wating for Cariection \\
\hline Denice 1 & $7 / 18 / 20128.30 \mathrm{AM}$ & & Wating For Coriection \\
\hline Device 1 & $7 / 16 / 20123: 20 \mathrm{PM}$ & & Wating For Conection \\
\hline Device I & $6 / 18 / 2012203 \mathrm{PM}$ & & Wating For Conection \\
\hline Dence 1 & 6/7e/201210 47 AM & & Wating fo Carection \\
\hline Device 1 & 6/74/201212 48 PM & & Wating Fo Coriection \\
\hline Device 1 & $6 / 6 / 201210: 11 \mathrm{AM}$ & & Wating Fo Conection \\
\hline Device I & $7 / 1 / 20111220 \mathrm{PM}$ & & Wating For Conection \\
\hline
\end{tabular}

By clicking on the individual sessions, the collected points that require correction can be used (Figure 13).

Figure 13. Trimble positions accuracy.

\begin{tabular}{|c|c|}
\hline \multicolumn{2}{|l|}{ Irribic fortions offec } \\
\hline \multicolumn{2}{|c|}{ Festures in the sostion frem [Dovise 1] etreed on $12 / 30 / 83912.00 .00$ AM: } \\
\hline Stohnt & E*t Aocurscy $(-1)$ \\
\hline TíniblPoints_Ee6ed7c1-4c00-4d838d710. Vald & 4.277 \\
\hline TimelePoins_2149305b9935-4706b3e00. Vald & 3.927 \\
\hline TimblePoirkt_55ac7720-466-4907.9066- Vald & 3.769 \\
\hline 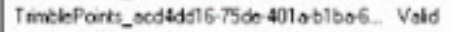 & 4.086 \\
\hline Thim:kePoirk_bdac2lcac1e1-4d378abise. Vaid & 3.984 \\
\hline 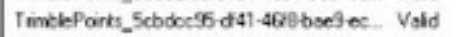 & 5.390 \\
\hline 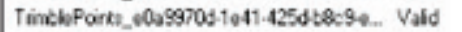 & 4.231 \\
\hline TtmelePorts_6od594o4_24lo-42559694.d. Vald & 4.827 \\
\hline 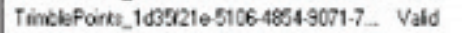 & 4.273 \\
\hline 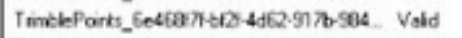 & 4.156 \\
\hline 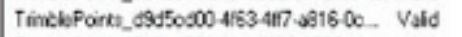 & 4.303 \\
\hline Ttimel-Points_719idf5-46ed43090575-11. Vald & 4.257 \\
\hline 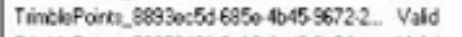 & 4.962 \\
\hline 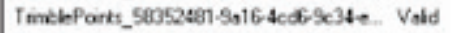 & 4.460 \\
\hline 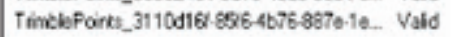 & 4.369 \\
\hline
\end{tabular}

The differential correction is run at the session level and can be run on a single session or multiple sessions at one time. The user can also run the correction multiple times, selecting different towers each time to try to achieve better results. The correction is initially performed on the Session Points layer and, upon completion, the Trimble Points layer is automatically updated with the corrected information.

Once the points are corrected, the user will need to correct the other data layers in the MXD to match the points. The Trimble office tools are able to correct only data that was actually collected on the device. In the field, when a point is collected, it is connected to a link table that allows the user to define which business features the point should relate to. This workflow 
allows users to be able to collect information about multiple features at once, without having to walk the track multiple times.

The "Regenerate Features" python script is designed to update the geographic location of all other related features in the database using the differentially corrected point information from the Trimble Points layer. Once this regeneration is complete, a final 'Calculate Stations' python script is run. This tool stores the linear reference data about where the stations exist along the track.

\section{RAILER integration/reporting}

Current reporting function leverages a RAILER export. After all data is corrected, it is then exported to RAILER from a stored procedure. This is a one-way export from the enterprise geodatabase to an Access template database. Currently, the Army uses an Access database for each inspection and installation. 


\section{Findings}

Overall, the ERIDS product has met expectations and functions as anticipated. Table 3 summarizes the specific goals and results for ERIDS:

Table 3. Goals and progress.

\begin{tabular}{|l|l|}
\hline \multicolumn{1}{|c|}{ Goal } & \multicolumn{1}{c|}{ Completed } \\
\hline Eliminate paper forms & Yes \\
\hline Enter data digitally & Yes \\
\hline Closed to traffic defect report generated at outbrief & Yes \\
\hline Streamline report generation (reduce from 90 to 45 days) & Yes \\
\hline Automate map generation & Yes \\
\hline Central data repository & Yes \\
\hline Integrate ultrasonic truck data & Yes \\
\hline
\end{tabular}

\section{ERIDS data collection}

The following diagram (Figure 14) represents the data collection workflow associated with the ERIDS product. The field data collection is completed with a team of certified track inspectors with a minimum of 2 per team for safety. 
Figure 14. ERIDS data collection workflow.

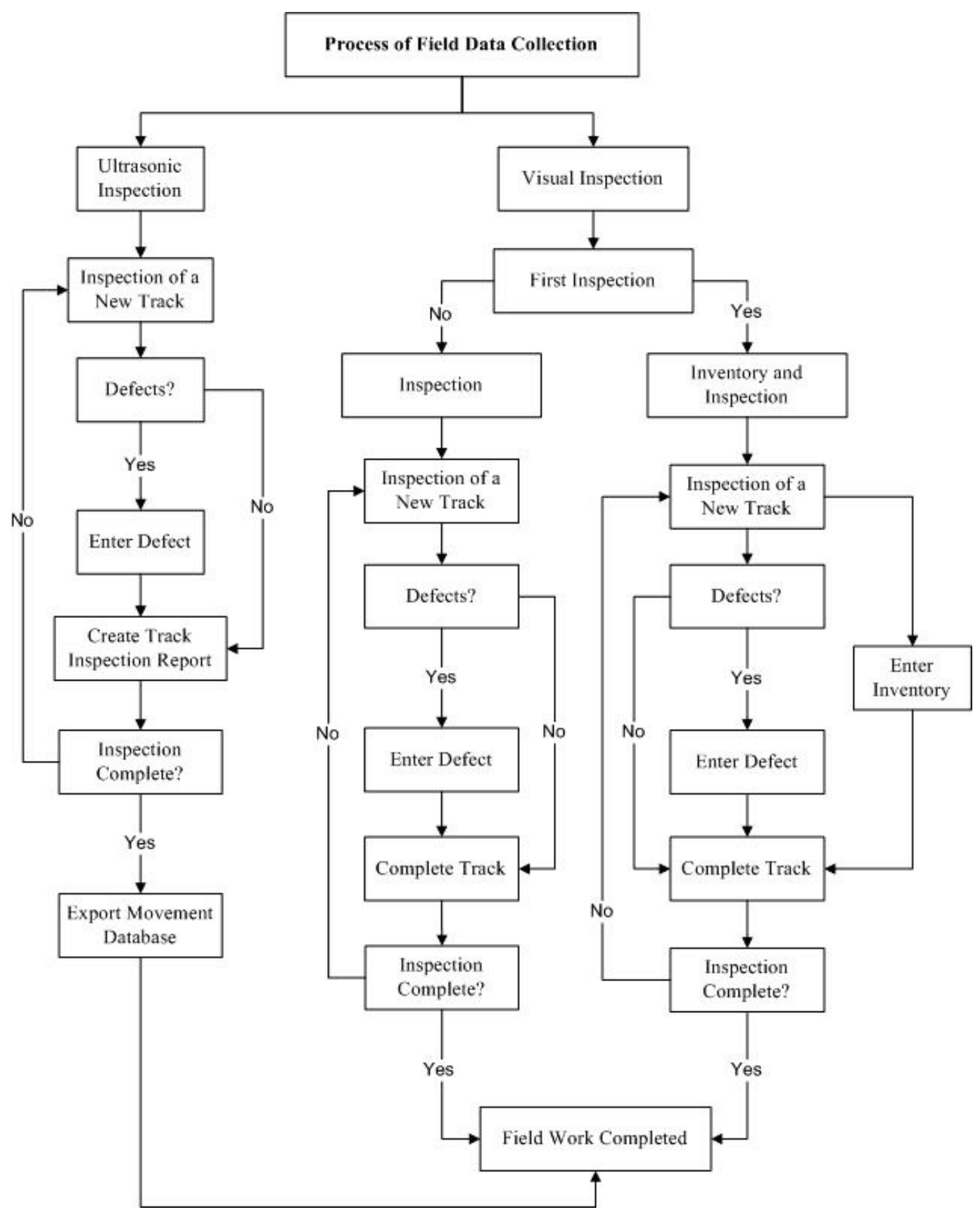

Screen captures from the device are represented in Figures 15 through 18. Workflow elements are closely matched to what the inspector sees on the handheld device. 
Figure 15. Screen shot of ERIDS main screen.

\begin{tabular}{|c|c|c|c|}
\hline $\begin{array}{l}\text { Collecting } 0 \text { Fea } \\
\text { Current Track: }\end{array}$ & ures & $\nabla$ & 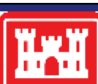 \\
\hline Comp Joint: & $200 \mathrm{ft}$ & & \\
\hline Turnout & & & \\
\hline Grade $X$-ing & & & \\
\hline Curve & & & \\
\hline Drainage & & & \\
\hline Appliance & & & \\
\hline F\&OTM Defect & & & \\
\hline Tie Cluster & & & \\
\hline Ballast Defect & & & \\
\hline Main Inventory Ins & ection Syn & & \\
\hline $\begin{array}{c}\text { Bad Ties } \\
0 \\
\end{array}$ & $\begin{array}{c}\text { issing Bolt } \\
0 \\
\end{array}$ & & $\begin{array}{l}\text { e Bolt } \\
0\end{array}$ \\
\hline
\end{tabular}

Figure 16. Screen shot of ERIDS drain feature.

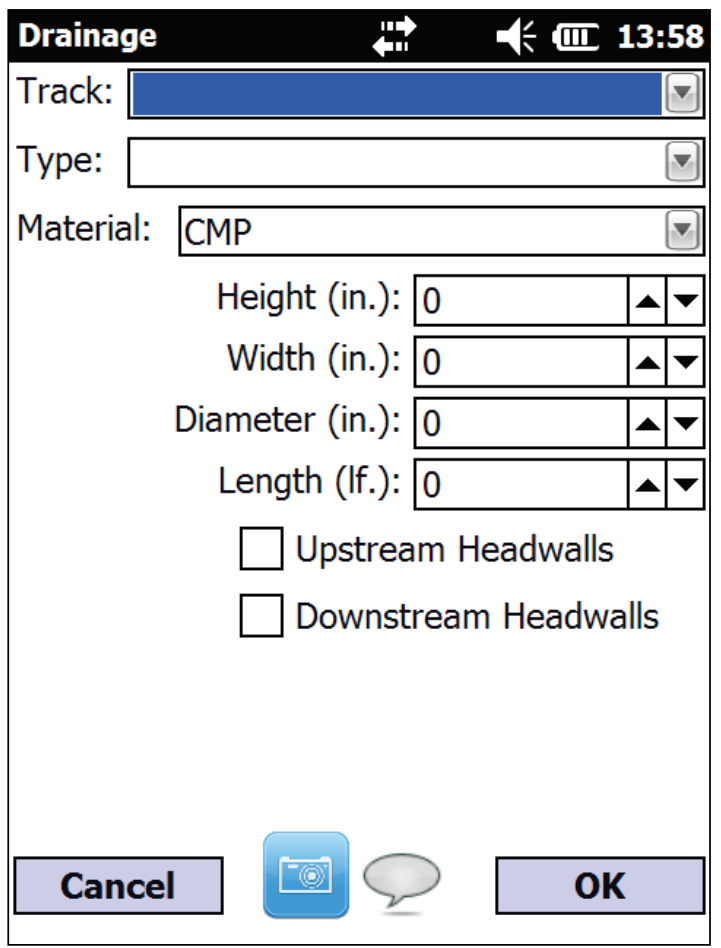


Figure 17. Screen shot of ERIDS inventory.

\begin{tabular}{|c|c|c|}
\hline \multicolumn{2}{|c|}{$\begin{array}{l}\text { Collecting } 0 \text { Features } \\
\text { Current Track: }\end{array}$} & \multirow{2}{*}{ 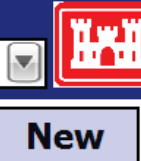 } \\
\hline TrackStructure & Edit & \\
\hline \multicolumn{2}{|l|}{ Appliance } & Add \\
\hline \multicolumn{2}{|l|}{ Turnout } & Add \\
\hline \multicolumn{2}{|l|}{ Rail X-ing } & Add \\
\hline Curve & Edit & New \\
\hline Bridge & Edit & New \\
\hline Grade & Edit & New \\
\hline Grade X-ing & Edit & New \\
\hline Restriction & Edit & New \\
\hline \multicolumn{2}{|l|}{ Drainage } & Add \\
\hline \multicolumn{3}{|c|}{ Main Inventory Inspection Sync } \\
\hline $\begin{array}{c}\text { Bad Ties } \\
0 \\
\end{array}$ & & $\begin{array}{l}\text { Loose Bolt } \\
0 \\
\end{array}$ \\
\hline
\end{tabular}

Figure 18. Screen shot of ERIDS inspection.

\begin{tabular}{|c|c|c|}
\hline \multicolumn{2}{|c|}{$\begin{array}{l}\text { Collecting } 0 \text { Features } \\
\text { Current Track: }\end{array}$} & D \\
\hline \multicolumn{2}{|l|}{ Rail Defect } & Add \\
\hline \multicolumn{2}{|l|}{ FOTM Defect } & Add \\
\hline \multicolumn{2}{|l|}{ Ballast Defect } & New \\
\hline Inspection Impaired & Edit & New \\
\hline \multicolumn{2}{|l|}{ Appliance Defect } & Add \\
\hline \multicolumn{2}{|l|}{ Drainage Defect } & Add \\
\hline \multicolumn{2}{|l|}{ Turnout Defect } & Add \\
\hline \multicolumn{2}{|l|}{ Tie Defect } & Add \\
\hline Manual Track Geom. & Edit & New \\
\hline \multicolumn{2}{|l|}{ Rail X Defect } & Add \\
\hline \multicolumn{2}{|l|}{ Grade X Defect } & Add \\
\hline \multicolumn{3}{|c|}{ Main Inventory Inspection Sync } \\
\hline \multicolumn{2}{|l|}{\begin{tabular}{||c|} 
Bad Ties \\
0 \\
\end{tabular}} & $\begin{array}{l}\text { Loose Bolt } \\
0 \\
\end{array}$ \\
\hline
\end{tabular}




\section{Data quality}

As a primary goal for the ERIDS application, data quality has been evaluated and documented through a comparison of paper forms versus digital data for three installations (Aberdeen Proving Ground, Sierra Army Depot, and Katterbach Kaserne). Overall findings indicate that data collection quality is unchanged from paper to digital. Improvements in determining the station location and accuracy within the Trimble's threshold and elimination of transcription errors were the two areas where data quality was improved.

Table 4 represents the improved accuracy in stationing from the wheel compared to the ERIDS handheld. These data are represented from Sierra Army Depot.

Table 4. Stationing accuracy.

\begin{tabular}{|l|l|l|l|}
\hline \multicolumn{2}{|c|}{ 2009 Pre-ERIDS Inspection } & \multicolumn{2}{c|}{ 2012 ERIDS Inspection } \\
\hline Track Segment & \multicolumn{1}{|c|}{ Segment Stations (ft) } & Track Segment & Segment Stations (ft) \\
\hline A 3 & $0+00-31+27$ & A 3 & $0+0.00-31+09.62$ \\
\hline A 7 & $0+00-20+27$ & A 7 & $0+0.00-20+27.46$ \\
\hline A 8 & $0+00-17+50$ & A 8 & $0+0.00-17+50.75$ \\
\hline Army 1 & $0+00-56+76$ & Army 1 & $0+0.00-61+86.90$ \\
\hline Army 2 & $0+00-42+82$ & Army 2 & $0+0.00-43+97.89$ \\
\hline B 10 & $0+00-43+95$ & B 10 & $0+0.00-43+85.07$ \\
\hline B 2 & $0+00-19+45$ & B 2 & $0+0.00-23+52.71$ \\
\hline B 6 & $0+00-12+56$ & B 6 & $0+0.00-12+55.68$ \\
\hline B 8 & $0+00-12+58$ & B 8 & $0+0.00-12+56.69$ \\
\hline BY 1 & $0+00-37+31$ & BY 1 & $0+0.00-43+20.00$ \\
\hline East Leg & $0+00-66+28$ & East Leg & $0+0.00-69+68.98$ \\
\hline Engine house 1 & $0+00-86+94$ & Engine House 1 & $0+0.00-87+76.76$ \\
\hline Interchange Y & $0+00-9+90$ & Interchange Y & $0+0.00-10+16.49$ \\
\hline Main Line & $0+00-125+99$ & Main Line & $0+0.00-126+55.45$ \\
\hline Ramp Lead & $0+00-53+71$ & Ramp Lead & $0+0.00-53+39.44$ \\
\hline Y Loop North & $0+00-9+88$ & Y Loop North & $0+0.00-9+55.85$ \\
\hline Y Loop South & $0+00-9+73$ & Y Loop South & $0+0.00-9+59.17$ \\
\hline Main Loop & $0+00-519+98$ & Main Loop & $0+0.00-519+15.88$ \\
\hline
\end{tabular}


The significance of the improved level of accuracy is represented in the ability of installation personnel to more easily and efficiently locate and repair identified defects.

Image quality generated from the ERIDS application is diminished from previous methods; however, it is geo-referenced and linked to defects.

\section{Adoption}

A combination of six certified track inspectors have tested and used the ERIDS product at the nine test facilities identified in Chapter 1. Table 5 indicates where inspectors tested and what element of the ERIDS product was tested.

Table 5. Testing matrix.

\begin{tabular}{|c|c|c|c|c|c|c|c|c|c|c|c|}
\hline & \multicolumn{10}{|c|}{ Installation } \\
\hline & & 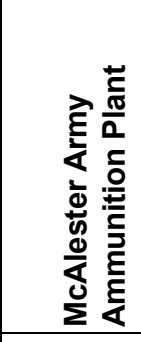 & 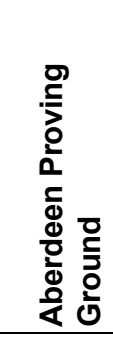 & 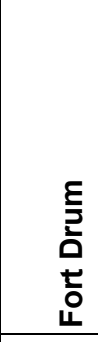 & 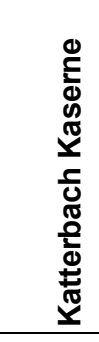 & 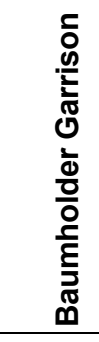 & $\begin{array}{l}\stackrel{y}{0} \\
\Phi \\
\frac{\Phi}{5}\end{array}$ & 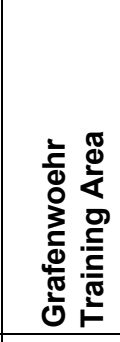 & 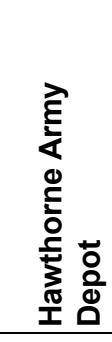 & 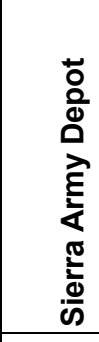 & 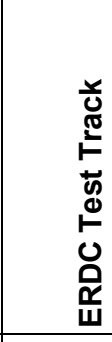 \\
\hline \multirow{8}{*}{ 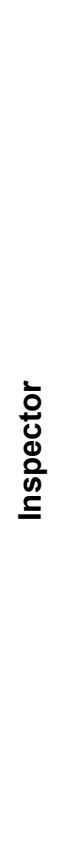 } & $\begin{array}{l}\text { T. Jeremy } \\
\text { Beasley }\end{array}$ & $\mathrm{HH} / \mathrm{UT}$ & $\mathrm{HH}$ & $\mathrm{HH}$ & $\mathrm{HH}$ & $\mathrm{HH}$ & $\mathrm{HH}$ & $\mathrm{HH}$ & $\mathrm{HH}$ & $\mathrm{HH}$ & $\mathrm{HH} / \mathrm{UT}$ \\
\hline & \begin{tabular}{|l} 
Chad \\
Gartrell
\end{tabular} & $\mathrm{HH} / \mathrm{UT}$ & & & $\mathrm{HH}$ & $\mathrm{HH}$ & $\mathrm{HH}$ & $\mathrm{HH}$ & & & \\
\hline & $\begin{array}{l}\text { Anthony } \\
\text { Falls }\end{array}$ & & & & $\mathrm{HH}$ & $\mathrm{HH}$ & $\mathrm{HH}$ & $\mathrm{HH}$ & $\mathrm{HH}$ & $\mathrm{HH}$ & \\
\hline & $\begin{array}{l}\text { Michael } \\
\text { Crawford }\end{array}$ & UT & & & & & & & & & UT \\
\hline & $\begin{array}{l}\text { Donald } \\
\text { Embry }\end{array}$ & $\mathrm{HH}$ & & & $\mathrm{HH}$ & $\mathrm{HH}$ & $\mathrm{HH}$ & $\mathrm{HH}$ & $\mathrm{HH}$ & & $\mathrm{HH}$ \\
\hline & $\begin{array}{l}\text { Matthew } \\
\text { Norris }\end{array}$ & $\mathrm{HH}$ & & & & & & & $\mathrm{HH}$ & $\mathrm{HH}$ & $\mathrm{HH} / \mathrm{UT}$ \\
\hline & $\begin{array}{l}\text { Charles } \\
\text { Andrews }\end{array}$ & & & & $\mathrm{HH}$ & $\mathrm{HH}$ & $\mathrm{HH}$ & $\mathrm{HH}$ & $\mathrm{HH}$ & & \\
\hline & Jason Knox & & & & & & & & $\mathrm{HH}$ & $\mathrm{HH}$ & $\mathrm{HH}$ \\
\hline
\end{tabular}

$\mathrm{HH}=$ Handheld testing, UT= Ultrasonic truck testing. 
Onsite training consisted of an overview of the application and review of the digital versus paper process. The menu-driven design conformed to the workflow of the inspectors in such a way that limited training was necessary prior to use of the device for data collection.

Overall, field inspectors view the ERIDS application positively. Adoption survey results are presented in Appendix A. Table 6 summarizes the number of positive responses to each question.

Table 6. Summary of inspector survey results.

\begin{tabular}{|l|l|l|l|}
\hline \multicolumn{1}{|c|}{ Question } & $\begin{array}{c}\text { Number of } \\
\text { Positive } \\
\text { Responses }\end{array}$ & $\begin{array}{c}\text { Number of } \\
\text { Negative } \\
\text { Responses }\end{array}$ & $\begin{array}{c}\text { Number of } \\
\text { Non-responses }\end{array}$ \\
\hline $\begin{array}{l}\text { Question 1: Was the process } \\
\text { simplified/easy to change from the } \\
\text { paper inspection forms to the } \\
\text { electronic forms? }\end{array}$ & 6 & 0 & 1 \\
\hline $\begin{array}{l}\text { Question 2: Does the ERIDS make } \\
\text { your job easier? }\end{array}$ & 6 & 0 & 1 \\
\hline $\begin{array}{l}\text { Question 3: What improvements or } \\
\text { changes would you like to see made } \\
\text { going forward? }\end{array}$ & 5 & 0 & 2 \\
\hline
\end{tabular}

\section{ERIDS reporting}

Generation of the final report deliverable is accomplished via RAILER and the Report Writer, a custom VB .NET application that leverages queries in the RAILER database. Generation of the compiled final report occurs in four steps and is the responsibility of three separate individuals. The workflow below in (Figure 19) highlights process and responsibilities. 
Figure 19. RAILER processing workflow.

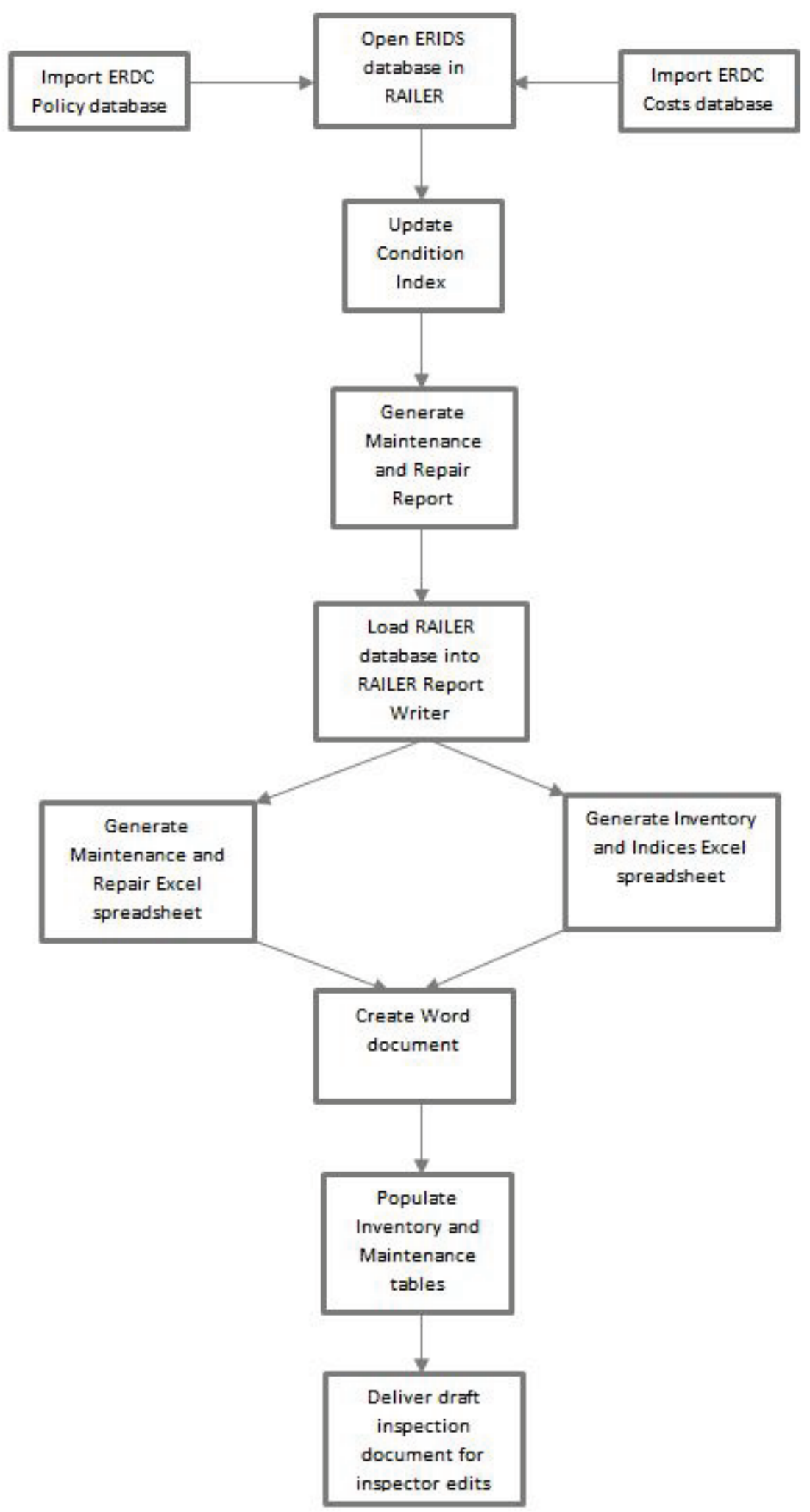




\section{Closed-to-traffic defect report}

Generation of the closed-to-traffic defect report (CTTDR) is through a stored procedure in the SQL central data repository. Ultrasonic data and sync with the database must occur prior to generation of the CTTDR. These steps provide scheduling challenges with respect to the outbrief at the installation. Specific locations for tie defects are now provided in the CTTDR. Additionally, the time and personnel necessary to generate the CTTDR for the outbrief is reduced by $50 \%$.

\section{RAILER exports}

RAILER database export was smoother than anticipated with only two items requiring modification during the export process. Business data collected within ERIDS was not the complete set of data necessary for RAILER to run properly. RAILER breaks an installation into "Areas" (i.e., on- or off-post), which is required for generation of the $M \& R$ plan. Areas were added to ERIDS and can be assigned to tracks before or after an inspection.

ERIDS does not require a user to explicitly mark an inventory item as defect-free. When the Condition Index update is performed in RAILER, a Track Segment Condition Index (TSCI) of -1 is generated, indicating no defects, and the track is not marked as defect free even though it is. The fix applied was to convert -1s to 100 indicating the track was defect-free.

\section{Final report generation}

\section{RAILER}

The use of RAILER to generate the final report document is proceeding as expected and in the normal pattern of the workflow. No modifications have been required to this step of the overall process.

\section{Report Writer}

Report Writer functions as expected. Queries within RAILER built to support Report Writer resulted in one instance of an M\&R plan providing results that were not displayed in a manner neither expected nor consistent with past reports (results appeared to be duplicates but were in fact correct). In the figures below, Table 7 shows an M\&R report with turnouts numbered and labeled. In Table 8 , the turnouts are not grouped or labeled, but the data are correct. 
Table 7. Example RAILER output.

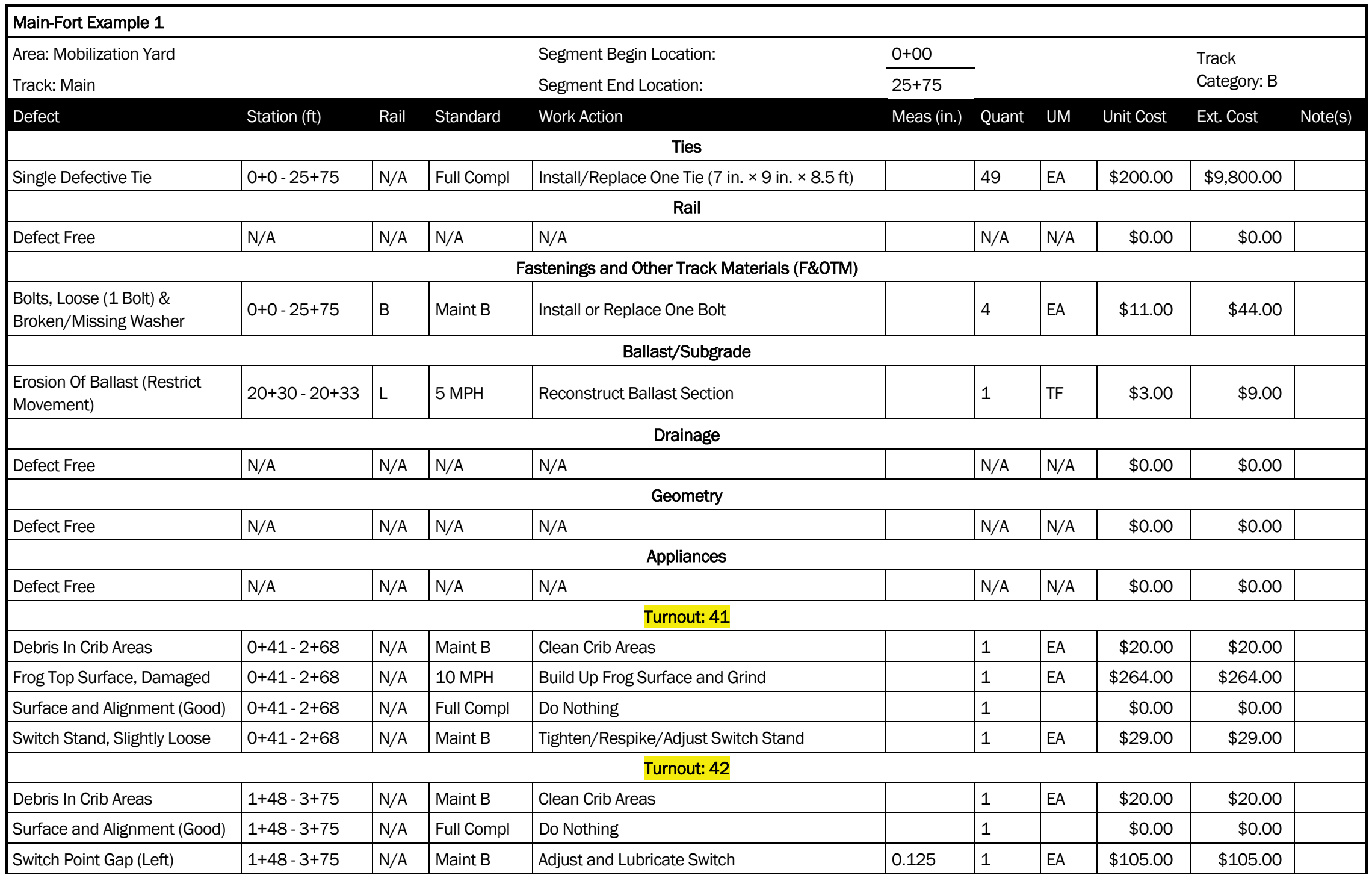


Table 8. Example ERIDS output.

\begin{tabular}{|c|c|c|c|c|c|c|c|c|c|c|}
\hline \multicolumn{11}{|c|}{ Main Line-Fort Example 2} \\
\hline \multicolumn{4}{|l|}{ Area: On Post } & Segment Begin Location: & \multicolumn{2}{|l|}{$0+0.00$} & & & \multirow{2}{*}{\multicolumn{2}{|c|}{$\begin{array}{l}\text { Track } \\
\text { Category: A }\end{array}$}} \\
\hline \multicolumn{4}{|l|}{ Track: Main Line } & Segment End Location: & \multicolumn{4}{|c|}{$126+55.45$} & & \\
\hline Defect & Station (ft) & Rail & Standard & Work Action & Meas (in.) & Quant & UM & Unit Cost & Ext. Cost & Note(s) \\
\hline \multicolumn{11}{|c|}{ Ties } \\
\hline Single Defective Tie & $0+0-126+55$ & N/A & Maint B & Install/Replace One Tie $(7$ in. $\times 9$ in. $\times 8.5 \mathrm{ft})$ & & 16 & EA & $\$ 200.00$ & $\$ 3,200.00$ & \\
\hline \multicolumn{11}{|c|}{ Rail } \\
\hline Bolt Hole Crack > $1.5 \mathrm{in}$. & $61+01$ & $\mathrm{~L}$ & $10 \mathrm{MPH}$ & Replace Rail With New Rail & & 1 & EA & $\$ 2,000.00$ & $\$ 2,000.00$ & \\
\hline Head/Web Separation > 4 in. & $68+25$ & $R$ & $\begin{array}{l}\text { Close to } \\
\text { Traffic } \\
\end{array}$ & Replace Rail With New Rail & & 1 & EA & $\$ 2,000.00$ & $\$ 2,000.00$ & \\
\hline $\begin{array}{l}\text { End Batter }=>0.375 \text { in. \& } \\
<0.5 \text { in. }(>3 / 8-\leq 1 / 2)\end{array}$ & $118+62$ & $R$ & $10 \mathrm{MPH}$ & Build Up Top of Rail and Grind & & 1 & EA & $\$ 264.00$ & $\$ 264.00$ & \\
\hline \multicolumn{11}{|c|}{ Fastenings and Other Track Materials (F\&OTM) } \\
\hline $\begin{array}{l}\text { Bolts, Missing/Cracked/Or } \\
\text { Broken (1 Bolt) }\end{array}$ & $60+64$ & $\mathrm{R}$ & Maint B & Install or Replace One Bolt & & 1 & EA & $\$ 11.00$ & $\$ 11.00$ & \\
\hline $\begin{array}{l}\text { Bolts, Missing Or Broken, All } \\
\text { on Rail End ( } 2 \text { Bolts) }\end{array}$ & $92+40-92+42$ & $R$ & $\begin{array}{l}\text { Close to } \\
\text { Traffic } \\
\end{array}$ & Install or Replace Two Bolts & & 1 & EA & $\$ 22.00$ & $\$ 22.00$ & \\
\hline $\begin{array}{l}\text { Bolts, Loose (1 Bolt) \& } \\
\text { Broken/Missing Washer }\end{array}$ & $126+55$ & N/A & Maint B & Install or Replace One Bolt & & 9 & EA & $\$ 11.00$ & $\$ 99.00$ & \\
\hline \multicolumn{11}{|c|}{ Ballast/Subgrade } \\
\hline Defect Free & N/A & N/A & N/A & N/A & & N/A & N/A & $\$ 0.00$ & $\$ 0.00$ & \\
\hline \multicolumn{11}{|c|}{ Drainage } \\
\hline Defect Free & N/A & N/A & N/A & N/A & & N/A & N/A & $\$ 0.00$ & $\$ 0.00$ & \\
\hline \multicolumn{11}{|c|}{ Geometry } \\
\hline Defect Free & N/A & N/A & N/A & N/A & & N/A & N/A & $\$ 0.00$ & $\$ 0.00$ & \\
\hline \multicolumn{11}{|c|}{ Appliances } \\
\hline Defect Free & $\mathrm{N} / \mathrm{A}$ & N/A & $\mathrm{N} / \mathrm{A}$ & N/A & & $\mathrm{N} / \mathrm{A}$ & N/A & $\$ 0.00$ & $\$ 0.00$ & \\
\hline \multicolumn{11}{|c|}{ Turnout: } \\
\hline Gauge At Frog Point (Right) & $0+0$ & N/A & Maint B & Correct Gauge & & 1 & EA & $\$ 255.00$ & $\$ 255.00$ & \\
\hline Gauge At Switch Points & $0+0$ & N/A & Maint B & Correct Gauge & & 1 & EA & $\$ 255.00$ & $\$ 255.00$ & \\
\hline Heel Joint Bolts (Left), Loose & $0+0$ & N/A & $5 \mathrm{MPH}$ & Tighten Heel Bolts & & 1 & EA & $\$ 10.00$ & $\$ 10.00$ & \\
\hline Surface and Alignment (Good) & $0+0$ & N/A & Maint B & Do Nothing & & 1 & & $\$ 0.00$ & $\$ 0.00$ & \\
\hline
\end{tabular}




\section{Map generation}

Prior to the use of the ERIDS, the map-generation process consisted of onscreen digitization of rail and turnout features (Figure 20). This process was lengthy, and it lacked the ability to show individual defects in detail. With the implementation of the ERIDS, all spatial features collected in the field are available for representation on the map (Figure 21) and the need for digitization is eliminated from the process.

Figure 20. Map of Sierra Army Depot prior to ERIDS field implementation.

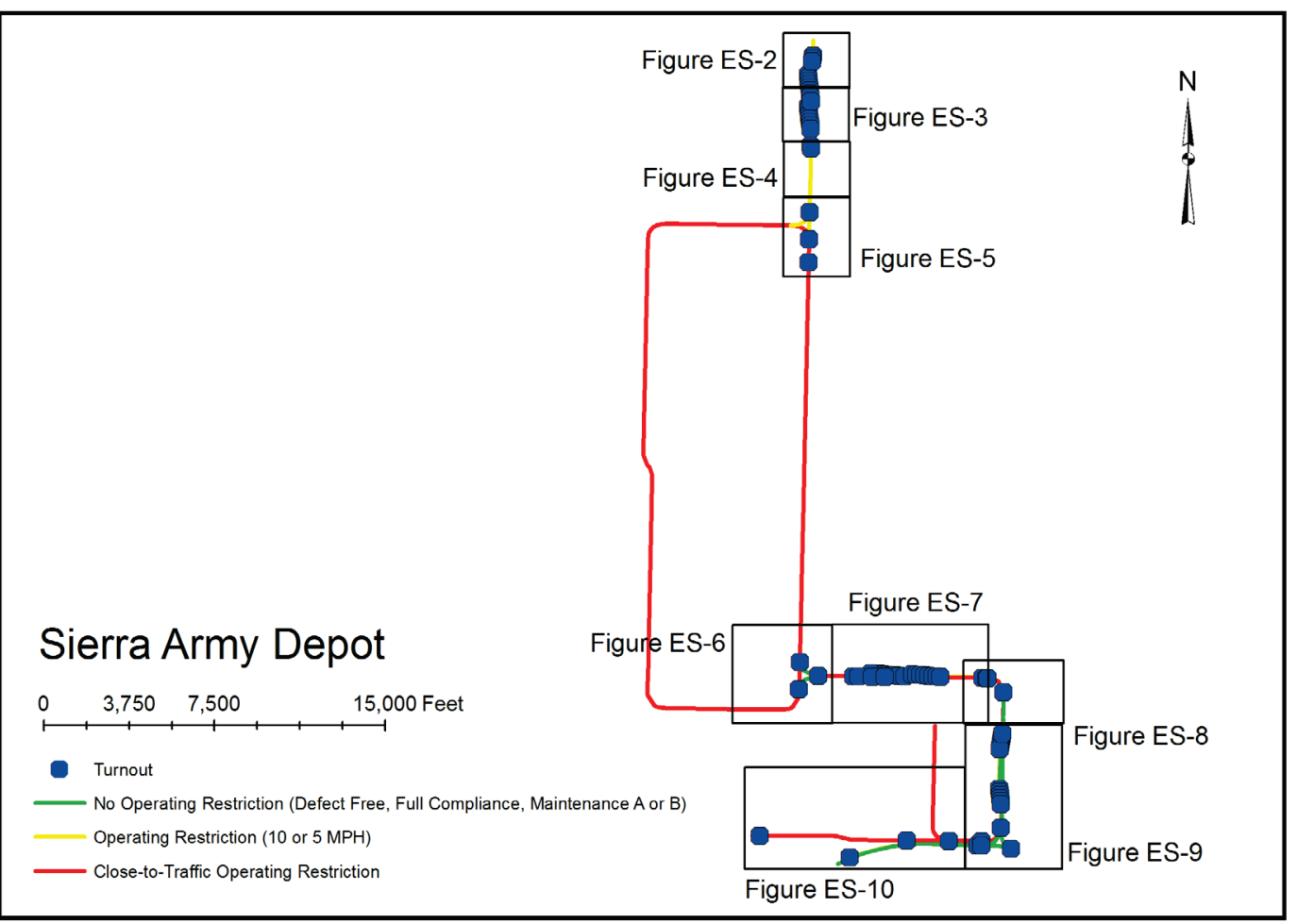


Figure 21. Map of Sierra Army Depot after ERIDS data collection.

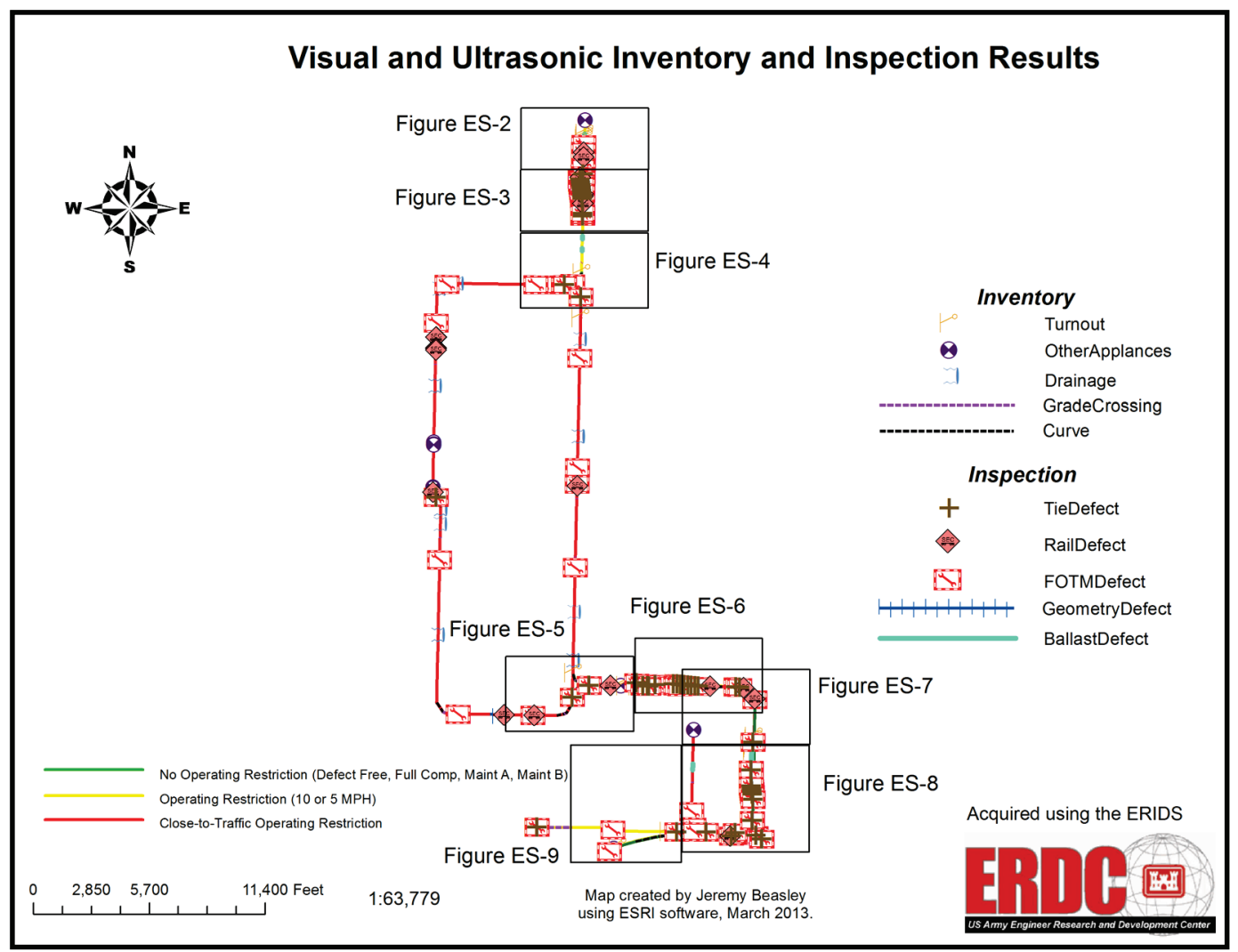




\section{Conclusions and Recommendations}

The purpose of this project was to address the business and technical needs of the Railroad Inspection Program through the following:

- Automate and improve data collection techniques

- Enhance report generation and analysis methods

- Implement a geo-enabled enterprise integration and data management solution

This was accomplished by development of ERIDS, a new mobile data collection/inspection application integrated with the ability to export the data to a format that can be consumed by the existing RAILER software for use in reporting.

\section{Conclusions}

As noted in previous sections, the three main project goals were met with good adoption by the field inspection staff. Other high-level conclusions that can be gleaned from the process, development, and implementation are as follows:

- The functionality of this data collection system could be extended to other infrastructure inspection programs. Lessons learned that could be applied include:

○ Workflow considerations

- Adoption

- Requirements methods

○ Architecture

- Multi-feature collection capability with differential correction was a significant technical challenge that was overcome.

- Working with a legacy system institutes some integration constraints that warrant thorough testing 


\section{ERIDS functionality}

Implementation and deployment of the ERIDS product improved work efficiency. There remains today a single temporal issue that requires a restart of session after $4 \mathrm{hr}$ of data collection. If an inspector runs the application for longer than the 4-hr period, it crashes and the inspector is unable to start collecting a new track structure and/or turnout. At the time of publication this is managed by human workflow -- save and restart on 4-hr intervals.

\section{Overall workflow implications}

With improved work efficiency on the data collection side also comes a reduction in time required for data entry once the inspector has left the track. Also on the back end of the process has been improved accuracy of data collected, reduced effort for CTTDR, reduced time in final report generation, and reduced time/effort for map generation. Currently, inventory is being collected for all sites with ERIDS now, which adds some time in the field for actual data collection efforts. For repeat inspections, these sites will be reduced in actual data collection time as well.

\section{Technical summary}

Each component of the ERIDS system plays a part in its overall success. ArcGIS Mobile, SQL, Trimble Positions, and the ultrasonic product integrated effectively to produce positive results.

- The ArcGIS Mobile solution provided a business-oriented framework and facilitated alignment of workflow to stakeholder needs. This alignment-fed adoption as well "make(s) the job easier on the tracks inspector and it saves time."

- The SQL-enterprise database with paired mobile component facilitated syncing non-spatial data.

- Trimble Positions software allowed for differential correction hardware (GNSS capable).

- Ultrasonic inspection data is entered electronically and data is delivered electronically.

\section{Recommendations}

Recommendations resulting from the outcome of this project were numerous. Each team member and inspector took each of the successes 
and generated additional items that were relevant to the continuous improvement of the ERIDS system. The list below is representative of items viewed to be most significant in the near and mid-term future of ERIDS (o to $2 \mathrm{yr}$ ).

- Dashboards

- Enterprise dashboards -- Facilitate the ability of the Railroad program lead and Army executives to view, plan, and report spatially.

- Administrative dashboard -- Enable the Railroad program lead to add new inspection, generate station numbering, export to RAILER, CTTDR generation (compilation of the current scripts and stored procedures)

- Operations and maintenance

- Bug fixes

- COTS software upgrades

- Security patches

- Firmware upgrades

- Change management -- improvement suggestions from the field. Continuous improvement considerations based on enhancements to COTS elements.

- Installation mileage calculator

- Elevation values (z from GPS) to map in 3-D

- Pre-inspection track name loading for the UT truck

- Update condition indices and generate M\&R plan at the enterprise level

- Update report writer to generate final report from enterprise database

- Continuously review hosting considerations to evaluate long-term cost implications of buying hardware on a regular cycle. Alignment with USACE and U.S. Army IT initiatives. 


\section{References}

Grussing, M. N. 2009. RAILER engineered management system fact sheet. http://www.erdc.usace.army.mil/pls/erdcpub/!www_fact_sheet.

Headquarters, Departments of the Army, Navy, and Air Force. 2008. Unified facilities criteria, railroad track maintenance and safety standards. UFC 4-860-03. Washington, DC.

Selig, T., S. S. Smith, and G. R. Olhoeft. 2006. Ground penetrating radar for railway substructure condition assessment. Exton, PA: Bentley Systems Inc. 


\section{Appendix A - Adoption Survey Results}

\section{Survey questions}

Question 1: Was the process simplified/easy to change from the paper inspection forms to the electronic forms?

Question 2: Does the ERIDS make your job easier?

Question 3: What improvements or changes would you like to see made going forward?

\section{Survey results}

Inspector 1:

Question 1: Was the process simplified/easy to change from the paper inspection forms to the electronic forms?

For me it was easy to switch from paper to the handheld unit due to my familiarity with the system format (RAILER). Also, I believe anyone with some little exposure will be able to pick it up very quickly.

Question 2: Does the ERIDS make your job easier?

Yes, an inspector does not have to carry as much gear when using the ERIDS and there is a single location to enter all data instead of using multiple inspection sheets. In the field the ERIDS may be a little slower than writing on paper, but with the ERIDS an inspector only has to input the data once. Also, an inspector is now able to obtain a very accurate map of the track system and defects.

Question 3: What improvements or changes would you like to see made going forward?

I would like to see an auto adjust for stationing in between collection points (in the field) and a voice recognition data entry system instead of typing. 


\section{Inspector 2:}

Question 1: Was the process simplified/easy to change from the paper inspection forms to the electronic forms?

Yes

Question 2: Does the ERIDS make your job easier?

Eventually, yes

Question 3: What improvements or changes would you like to see made going forward?

Make ERIDS compatible with Report Writer to generate reports. Make edits in the field, for example, if a track structure was ended and wasn't supposed to be ended...be able to edit and pick the track structure back up.

\section{Inspector 3:}

Question 1: Was the process simplified/easy to change from the paper inspection forms to the electronic forms?

Yes

Question 2: Does the ERIDS make your job easier?

Yes

Question 3: What improvements or changes would you like to see made going forward?

I would like to keep up with footage as I walk down the track.

\section{Inspector 4:}

Question 1: Was the process simplified/easy to change from the paper inspection forms to the electronic forms? 
Question 2: Does the ERIDS make your job easier?

Yes it makes the job easier on the tracks inspector and it saves time.

Question 3: What improvements or changes would you like to see made going forward?

$\mathrm{N} / \mathrm{A}$

Inspector 5

Question 1: Was the process simplified/easy to change from the paper inspection forms to the electronic forms?

Yes

Question 2: Does the ERIDS make your job easier?

Yes

Question 3: What improvements or changes would you like to see made going forward?

I would like to see some improvements on mobility when walking track; including being able to back up if something was missed. Fixing some of the bugs that are causing the system to have to be rebooted in order to continue. Overall I am pleased with it. Keep up the good work.

\section{Inspector \#6}

Question 1: Was the process simplified/easy to change from the paper inspection forms to the electronic forms?

Yes

Question 2: Does the ERIDS make your job easier?

Absolutely

Question 3: What improvements or changes would you like to see made going forward? 
Possibly the addition of satellite imagery to the map, or perhaps a simplified geological survey type map. Would like to see the addition of measuring devices, such as some type of digital tape measure, distance measuring device, or other to make measurements easier to do, more accurate, and easier to record. Maybe the turnout pages could be automated to query for a measurement with a blue-tooth measure device then supplying the measurement automatically. Possibility of integrating this system into a cart that would contain an automated tie inspection system that could "thump" or examine the tie using GPR or other to determine the tie condition and automatically put that information into the hand-held by blue tooth or hard wire. Might also look at an automated ballast analyzer that could use sound, light, or GPR to measure ballast depth and determine if the ballast is at tie level or below and then automatically feed that data to the inspection device to determine insufficient ballast or sufficient ballast. Some of this technology might also be able to determine fouled or not fouled. Even further out might be LIDAR or other that could be combined with vegetation models to determine vegetation on or around the track that could also feed into the handheld using pre-set limits on the vegetation and extent allowed. 


\section{Unit Conversion Factors}

\begin{tabular}{|l|c|l|}
\hline Multiply & By & To Obtain \\
\hline Feet & 0.3048 & meters \\
\hline inches & 0.0254 & meters \\
\hline miles (U.S. statute) & $1,609.347$ & meters \\
\hline miles per hour & 0.44704 & meters per second \\
\hline tons (2,000 pounds, mass) & 907.1847 & kilograms \\
\hline tons (2,000 pounds, mass) per square foot & $9,764.856$ & kilograms per square meter \\
\hline yards & 0.9144 & meters \\
\hline
\end{tabular}





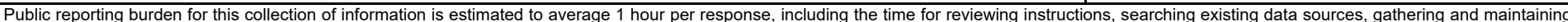

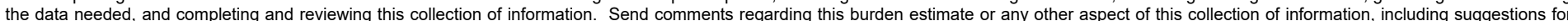

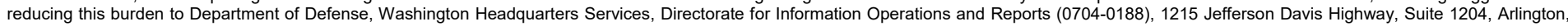

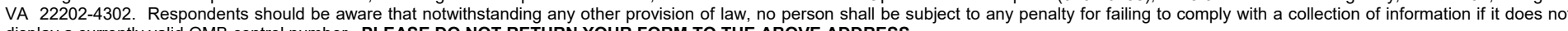
display a currently valid OMB control number. PLEASE DO NOT RETURN YOUR FORM TO THE ABOVE ADDRESS.
1. REPORT DATE (DD-MM-YYYY) 2. REPORT TYPE
3. DATES COVERED (From - To)

September 2020 Final

\section{TITLE AND SUBTITLE}

Electronic Railroad Inspection Database System for Military Facilities

5a. CONTRACT NUMBER

5b. GRANT NUMBER

5c. PROGRAM ELEMENT NUMBER

\section{AUTHOR(S)}

T. Jeremy Beasley, Anthony J. Falls, Chad A. Gartrell, Lora L. Johnson, Judy Reagan, and Caleb Carter

\section{5d. PROJECT NUMBER 403398}

5e. TASK NUMBER

5f. WORK UNIT NUMBER

8. PERFORMING ORGANIZATION REPORT NUMBER

ERDC/GSL TR-20-35

Geotechnical and Structures Laboratory

U.S. Army Engineer Research and Development Center

3909 Halls Ferry Road

Vicksburg, MS 39180-6199

\section{SPONSORING / MONITORING AGENCY NAME(S) AND ADDRESS(ES)}

Headquarters, Installation Management Command

G4 Public Works Division Facilities Management Branch

2405 Gun Shed

Fort Sam Houston, TX 78234-1223

10. SPONSOR/MONITOR'S ACRONYM(S)

HQ IMCOM

11. SPONSOR/MONITOR'S REPORT NUMBER(S)

\section{DISTRIBUTION / AVAILABILITY STATEMENT}

Approved for public release; distribution is unlimited.

\section{SUPPLEMENTARY NOTES}

\section{ABSTRACT}

The U.S. Army Engineer Research and Development Center (ERDC) executes inspection programs as part of the U.S. Army Transportation Infrastructure Inspection Program (ATIIP). These inspections, monitoring, and assessment programs include airfields, bridges, dams, railroads, waterfront facilities, and ranges. To date, the process for these inspection programs has been manually intensive, time consuming, and difficult to scale. The ERDC is bringing digital business and spatial data collection methods to its inspection program for the military's railroad infrastructure. By combining GPS and GIS technologies into a mobile data collection solution, added efficiency and data quality have been brought to the field inspection workflow. This modernization effort also results in streamlined data processing and reporting. These improved processes will lead to higher quality data, better analysis of the new richer data content, and better decisions made by the end-users and stakeholders.

\section{SUBJECT TERMS}

Railroad infrastructure

RAILER GIS

Railroad tracks--Inspection

\section{SECURITY CLASSIFICATION OF:}

\begin{tabular}{|l|l|}
\hline a. REPORT & b. ABSTRACT \\
Unclassified & Unclassified \\
\hline
\end{tabular}

Railroad evaluation

GPS applications

Sustainment management

Data collection platforms
Data processing

Global Positioning System

Geographic Information systems

\begin{tabular}{l|c|c|}
\cline { 1 - 1 } \begin{tabular}{l|l} 
c. THIS PAGE \\
Unclassified
\end{tabular} & $\begin{array}{c}\text { 17. LIMITATION } \\
\text { OF ABSTRACT }\end{array}$ & $\begin{array}{c}\text { 18. NUMBER } \\
\text { OF PAGES }\end{array}$ \\
\cline { 3 - 4 } & SAR & 58 \\
\hline
\end{tabular}

19a. NAME OF RESPONSIBLE PERSON

19b. TELEPHONE NUMBER (include area code) 